Environmental Chemical Engineering

Elsevier Editorial System(tm) for Journal of Manuscript Draft

Manuscript Number: JECE-D-16-00973R2

Title: Sorption of cadmium (II) ion from aqueous solution onto sweet potato (Ipomoea batatas L.) peel adsorbent: characterisation, kinetic and isotherm studies.

Article Type: Research Paper

Keywords: sweet potato adsorbent, heavy metal, kinetics, isotherm, sorption, cadmium, kinetic modelling, equilibrium modelling, agricultural residue

Corresponding Author: Mr. Edidiong Asuquo, PhD

Corresponding Author's Institution: The University of of Manchester

First Author: Edidiong Asuquo, PhD

Order of Authors: Edidiong Asuquo, PhD; Alastair Martin

Abstract: Sweet potato peels was used for the removal of Cd (II) from aqueous solutions. The residue was characterised using SEM, EDX, XRF, N2 BET, TGA and ATR-FTIR. Sorption of Cd (II) was carried out by varying $p H$, contact time and initial ion concentration at $25{ }^{\circ} \mathrm{C}$ and the results showed a strong dependence of the ion removal on the adsorbate $\mathrm{pH}$ with optimum observed at $\mathrm{pH}$ 7. Kinetics of Cd (II) sorption indicates optimum time of 180 minutes and the removal of Cd (II) occurred via a fast initial uptake. This was modelled using the pseudo first, pseudo-second and intraparticle diffusion models. The pseudo-first order gave a better description of the uptake kinetics than the pseudo-second order model with an $r 2$ value of 0.99 . The intraparticle-diffusion model showed that sorption had multi-linear steps indicating that the intraparticlediffusion is not the only rate controlling step in Cd (II) sorption. FTIR analysis of the PTPS before and after adsorption of $\mathrm{Cd}$ (II) indicates that some functional groups such as hydroxyl, carbonyl and carboxylate groups may be involved in metal ion sorption. Isotherm modelling of $\mathrm{Cd}$ (II) sorption was carried out using the Langmuir and Freundlich isotherms using a non-linear optimisation. The Langmuir isotherm gave a better fit for $\mathrm{Cd}$ (II) sorption and maximum loading capacity (qmax) was 18mgg-1 with an isotherm constant of $5.21 \times 10-3 \mathrm{Lmg}-1$ and $r 2$ value of 0.99 at $25{ }^{\circ} \mathrm{C}$. Hence, the PTPS residue was found to be a promising adsorbent for Cd (II) removal from aqueous streams. 
School of Chem. Engineering \& Anal. Science, University of Manchester, Oxford Road, Manchester, M13 9PL, United Kingdom $18^{\text {th }}$ August, 2016

The Editor

Journal of Environmnetal Chemical Engineering

\section{Re-Submission of Manuscript}

Dear Sir/Madam,

We hereby re-submit the manuscript titled: sorption of cadmium (II) ion from aqueous solution onto sweet potato (Ipomoea batatas L.) peel adsorbent: characterisation, kinetic and isotherm studies to your journal for publication. The authors are grateful to the Editor for giving us an opportunity to resubmit the manuscript after revision. The points mentioned by the editor and the reviewers have been taken care of while preparing the revised version. In addition new references have been only added to substantiate points in the responses to the comments and for overall improvement of the technical quality of the manuscript. The changes in the revised manuscript are highlighted for your information.

The authors want to draw your attention to the first and second comments of reviewer \#1 and we want to indicate our displeasure at the attitude of recommending reference in the comment for inclusion the manuscript that are not relevant to the subject of discussion. This has made us presume that the reviewer in question want to carry out reviews for the purpose of increasing his citation and H-index and this should not be encouraged by this Journal. Thus, we will request the editor not to send any further manuscripts that we submit in future to this Journal to this reviewer.

I hope the manuscript will be considered for publication.

Yours faithfully

Edidiong Asuquo

Corresponding author 


\section{Response to Reviewers comments}

Reviewer \#1: Thanks for the revisions thus far. The paper has improved considerably. However, there are still some items that must be accounted for, and revisions are needed.

Response: The authors are grateful to the reviewers for their corrections that have been used to improve the quality of the manuscript. The comments below have also been used to update the manuscript and we are grateful to the Editor and reviewers for their meaningful contributions.

Comment

1. The resolution of the figures should be improved; for example figure 7 .

Response: The resolutions in the figures have been improved.

2. Peaks of Fig. 4,5 should be properly indexed.

Response: Both Figs. 4 \& 5 have been indexed based on their composition as obtained from the EDAX genesis software used to obtain the EDAX spectra.

3. Peaks and bands of Fig. 7, 8, should be labelled.

Response: The peaks and bands discussed in the FTIR of the adsorbent (Section 3.1.6) have been labelled on both figures.

4. Page 15; "The result shows that the surface area of the PTPS adsorbent was $1.91 \mathrm{~m} 2 \mathrm{~g}-1$. This indicates that the adsorbent did not have any significant surface area". This discussion requires to be completed, if the materials have no sig. surface area, then, what is make it good in your applications; pores, structure, etc. Please add the discussion to complete the idea 
Response: The discussion has been improved to convey the information obtained from the results and the trend in properties observed from previous studies as stated below:

The result shows that the surface area of the PTPS adsorbent was $1.91 \mathrm{~m}^{2} \mathrm{~g}^{-1}$. This indicates that the PTPS adsorbent did have a low surface area and this is similar to what has been reported in previous studies for some agricultural residues. These lignocellulosic residues are known to have low surface areas due to the nature of the cellulose, hemicellulose and lignin content in them. These results in these residues having wide pore size distributions due to the high percentage of mesopores/macropores within their network compared to micropores as can be observed in the pore size distribution in Fig.1. Furthermore, these wide pore size distributions of mesopores/macropores in the lignocellulosic materials make them suitable for liquid phase sorption as it facilitates diffusion of the adsorbate into the adsorbent structure (Ribeiro et al., 2015; Menendez-Diaz and Martin-Gullon, 2006). However, it should be noted that the sorption properties of these residues are not only dependent on the possession of large surface areas as since porosity alone is not the only criteria required for good adsorbents. In addition to porosity, the nature and types of functional groups on these materials which serve as active sites for sorption contributes significantly to their adsorption potential for target pollutants (organic or inorganic). Thus, lignocellulosic residues have been reported to possess a number of different functional groups on their surface such as phenolic, carboxylic, hydroxyl, amines and ether groups which act as sources of physical and chemical interactions that facilitates adsorption via a number of mechanisms that include; hydrogen bonding, electrostatic interactions and surface complexation (Tan et al., 2015; Nguyen et al., 2013; Barkar et al., 2013; Bailey et al., 1999). Martin-Lara et al., (2013) in their study on the development and characterisation of biosorbents to remove heavy metals from aqueous solutions by chemical treatment of Olive stone observed that the Olive stone residue had a BET surface area of $0.163 \mathrm{~m}^{2} \mathrm{~g}^{-1}$ and a $\mathrm{Pb}^{2+}$ loading capacity of $6.32 \mathrm{mgg}^{-1}$, thereby indicating that surface area alone is not the only indicator of a good adsorbent. 
5. Being in line with what has been reported in previous studies is not enough; you please add scientific discussion of your finding as well.

Response: The discussion has been updated: See-

The small pore volume of the PTPS residue may be due to the nature of arrangement of cellulose, hemicellulose and lignin structures within the lignocellulosic framework of the material which may lead to the development of few number pores or blocked pores if they exist (Bota et al., 1996).

\section{Same for other characterization sections / results}

Response: The characterisation was discussed based on the results obtained and the use of previous studies in the discussion is to place the material in the context of similar research which confirms the trend observed.

7. Why is it important to have the 3.1.3 Chemical composition of adsorbent; for the application in adsorption?

Response: The adsorbent chemical composition is important as it gives information on the chemical species within the material which is useful in the discussion of the material behaviour during sorption- See- Martin-Lara et al., (2013) Development and characterisation of biosorbents to remove heavy metals from aqueous solutions by chemical treatment of Olive stone. Industrial \& Engineering Chemistry Research, 52: 10809-10819.

8. As shown in Fig 7,8, are these functional groups indicating the chemisorption or physisorption

Response: The functional groups both indicate that the PTPS adsorbent may have possibly interacted with the $\mathrm{Cd}(\mathrm{II})$ ions via chemical and physical sorption. This is based on presence of the functional groups- $\mathrm{C}=\mathrm{O}, \mathrm{C}-\mathrm{O}, \mathrm{NH}_{2}$ and $\mathrm{O}-\mathrm{H}$ groups and their variations after adsorption which may be used to infer hydrogen bonding and 
electrostatic interactions as well as complexation reactions as discussed in section 3.2.5- "mechanism of $\mathrm{Cd}(\mathrm{II})$ ion sorption" in the manuscript.

9. Why there a decrease in acidity (Table 3).

Response: The explanation is presented below;

The sorption of Cd(II) by the PTPS adsorbent may occur via a process that starts by the deprotonation of groups such as $-\mathrm{COOH},-\mathrm{NH}_{2}$ leading to release of $\mathrm{H}^{+}$into the adsorbate system. The $\mathrm{Cd}(\mathrm{II})$ ions which are positively charged are thereafter attracted to the active adsorption sites- which are negatively charged $\left(\mathrm{COO}^{-}, \mathrm{NH}_{2}\right.$ groups) and becomes coordinated with the deprotonated functional groups via coordinating bonding to the form an adsorbent metal complex. This scenario has been illustrated by Vaghetti et al., (2009). Pecan nutshell as biosorbent to remove $\mathrm{Cu}$ (II), Mn (II), and Pb (II) from aqueous solutions, Journal of Hazardous Materials, 162: 270-280. This mechanism of proton release during the surface complexation step may account for the decrease in the $\mathrm{pH}$ of the adsorbate after sorption between the $\mathrm{pH}$ 6-8 where there was substantial $\mathrm{Cd}(\mathrm{II})$ sorption which reduces as the $\mathrm{pH}$ further increases up till $\mathrm{pH} 10$.

10. Table 6 is to be updated; Journal of Molecular Liquids (2013) 188, 136-142

Response: Table 6 has been updated with qmax parameter values from previous studies based on cadmium sorption on lignocellulosic materials to provide a similar basis for direct comparison.

11. Page 6, introduction, "These approaches have 12 been reported to either be too expensive for the treatment and disposal...." Please add Environmental Science and Pollution Research (2013) 20 (5), 2828-2843

Response: The references cited in that paragraph are sufficient for the information it conveys. 
12. Page 6 after "that can be used as alternatives to activated carbon that are less expensive and readily" pls add Advances in colloid and interface science (2014) 211, 93-101.

Response: The authors wish to observe that the references cited in the aforementioned paragraph are sufficient for the discussion. In addition, the referred reference by the reviewer (Advances in colloid and interface science (2014) 211, 93 101 ) is a review relating to the "Processing methods, characteristics and adsorption behaviour of tire derived carbons" and is not relevant to the context of the study reported in this manuscript which relates to lignocellulosic derived adsorbents.

13. The MS requires refine for errors, typos, like missing full-stop, using of correct verbs, etc

Response: The manuscript has been updated to correct errors.

Reviewer \#4: The revised manuscript deems to be convincing in the present work. I recommend the manuscript to be accepted.

Response: The authors are grateful to the reviewer for the contributions that were used to improve the quality of the manuscript. 


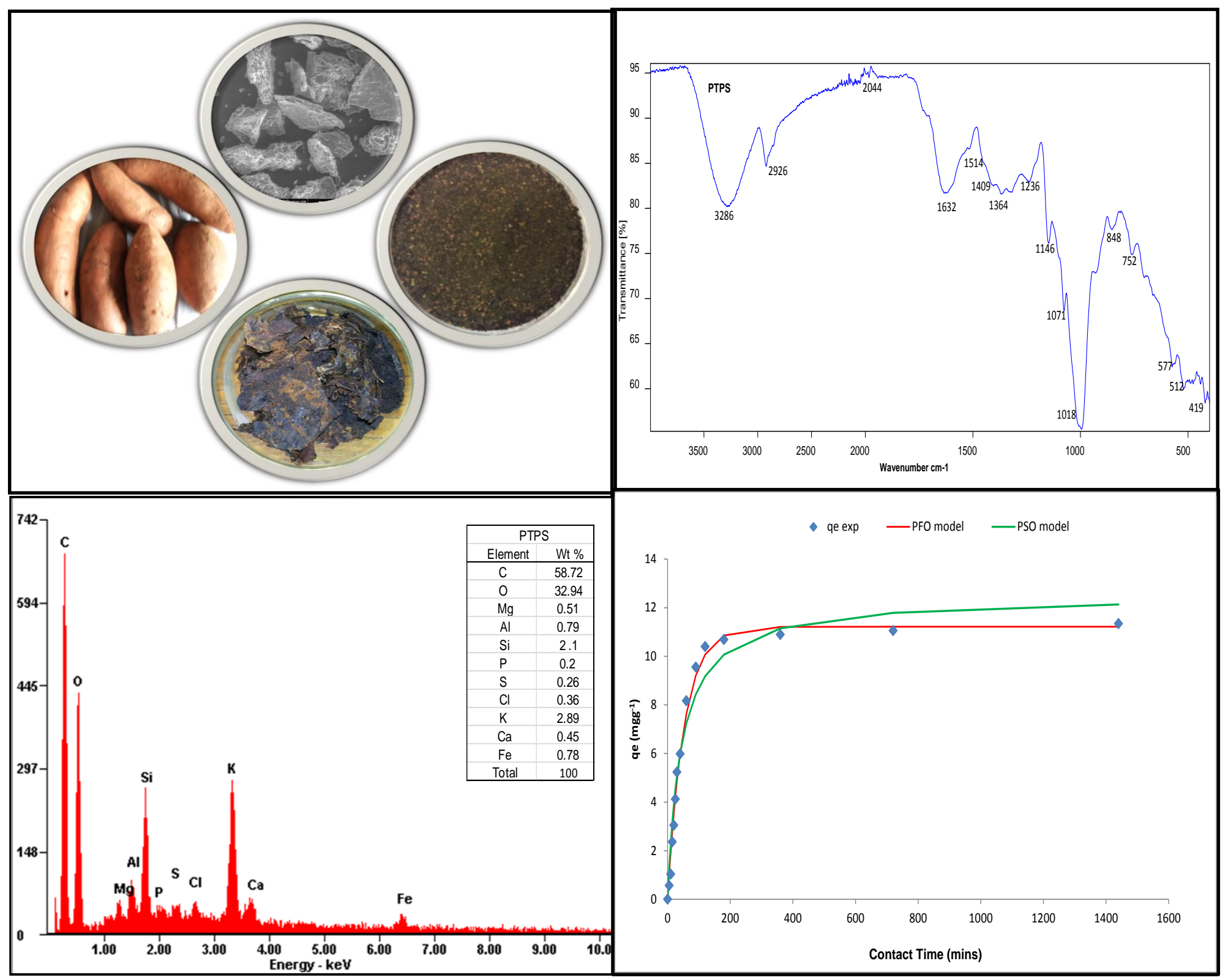




\section{Highlights}

- Cheap and available resource for heavy metal pollution remediation

- Characterisation of $\mathrm{Cd}(\mathrm{II})$ ion removal using waste as adsorbent

- Dependence of metal ion sorption on adsorbate $\mathrm{pH}$

- Intraparticle-diffusion modelling indicated multi linear rate controlling diffusion steps

- Isotherm modelling using non-linear optimisation technique was used to obtain the maximum loading of the metal ion. 
Sorption of cadmium (II) ion from aqueous solution onto sweet potato (Ipomoea batatas L.) peel adsorbent: characterisation, kinetic and isotherm studies.

Edidiong D. Asuquo ${ }^{1}$ and Alastair D. Martin ${ }^{1,2}$

${ }^{1}$ School of Chemical Engineering and Analytical Science, University of Manchester, Oxford Road, Manchester, M13 9PL, United Kingdom.

${ }^{2}$ Alastair Martin -Present address-

Department of Engineering, Lancaster University, Bailrigg, Lancaster LA1 4YR.United Kingdom

*Corresponding author. +441612003975

E-mail address: edidiong.asuquo@postgrad.manchester.ac.uk 


\section{Highlights}

- Cheap and available resource for heavy metal pollution remediation

- Characterisation of $\mathrm{Cd}(\mathrm{II})$ ion removal using waste as adsorbent

- Dependence of metal ion sorption on adsorbate $\mathrm{pH}$

- Intraparticle diffusion modelling indicated multi linear rate controlling diffusion steps

- Isotherm modelling using non-linear optimisation technique was used to obtain the maximum loading of the metal ion.

\section{Graphical Abstract}

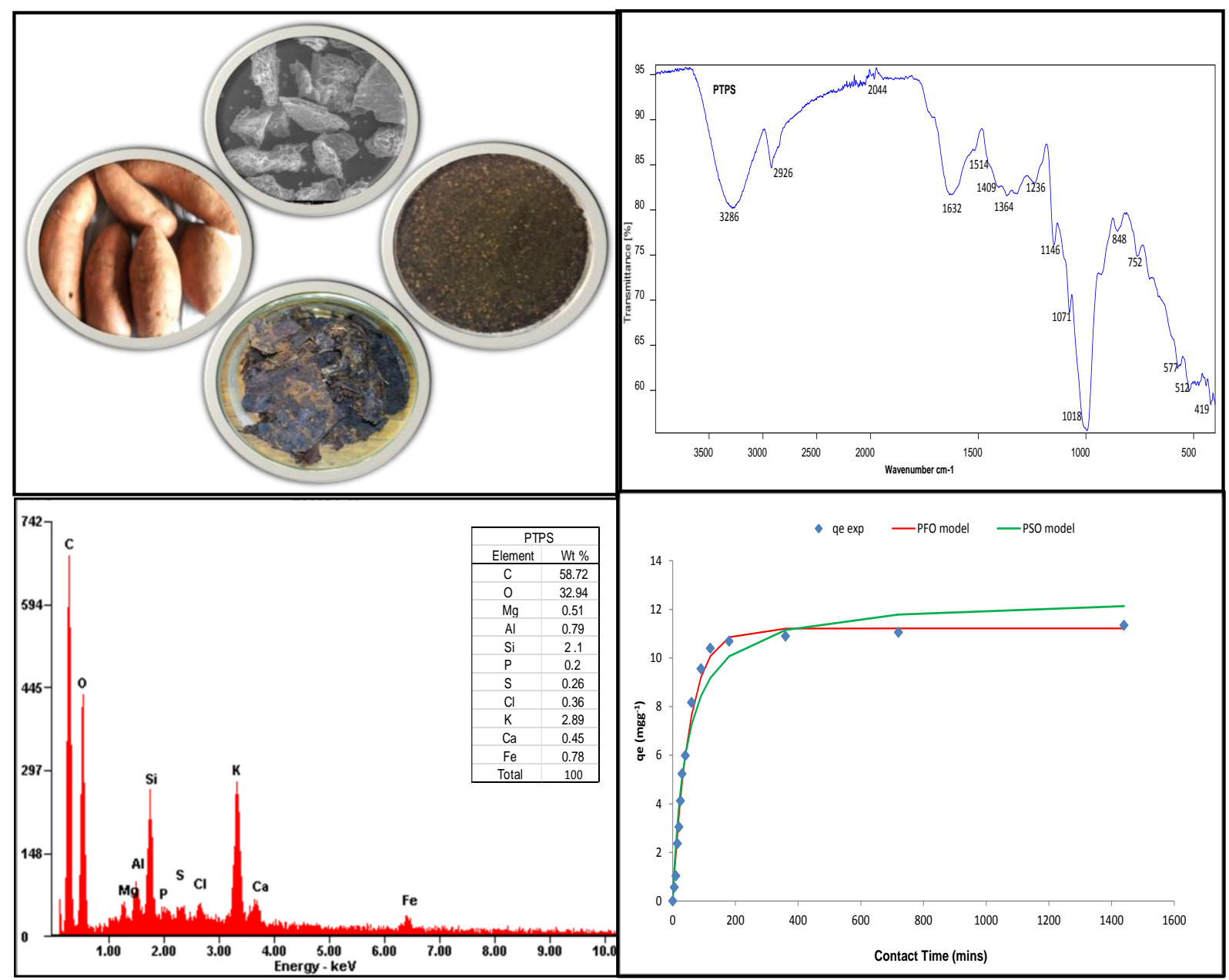




\begin{abstract}
Sweet potato peels was used for the removal of Cd (II) from aqueous solutions. The residue was characterised using SEM, EDX, XRF, $\mathrm{N}_{2}$ BET, TGA and ATR-FTIR. Sorption of Cd (II) was carried out by varying $\mathrm{pH}$, contact time and initial ion concentration at $25{ }^{\circ} \mathrm{C}$ and the results showed a strong dependence of the ion removal on the adsorbate $\mathrm{pH}$ with optimum observed at $\mathrm{pH} 7$. Kinetics of $\mathrm{Cd}$ (II) sorption indicates optimum time of 180 minutes and the removal of Cd (II) occurred via a fast initial uptake. This was modelled using the pseudo first, pseudo-second and intraparticle diffusion models. The pseudo-first order gave a better description of the uptake kinetics than the pseudo-second order model with an $r^{2}$ value of 0.99. The intraparticle-diffusion model showed that sorption had multi-linear steps indicating that the intraparticle-diffusion is not the only rate controlling step in Cd (II) sorption. FTIR analysis of the PTPS before and after adsorption of Cd (II) indicates that some functional groups such as hydroxyl, carbonyl and carboxylate groups may be involved in metal ion sorption. Isotherm modelling of Cd (II) sorption was carried out using the Langmuir and Freundlich isotherms using a non-linear optimisation. The Langmuir isotherm gave a better fit for Cd (II) sorption and maximum loading capacity $\left(\mathrm{q}_{\max }\right)$ was $18 \mathrm{mgg}^{-1}$ with an isotherm constant of $5.21 \times 10^{-3} \mathrm{Lmg}^{-1}$ and $\mathrm{r}^{2}$ value of 0.99 at $25^{\circ} \mathrm{C}$. Hence, the PTPS residue was found to be a promising adsorbent for $\mathrm{Cd}$ (II) removal from aqueous streams.
\end{abstract}

Keywords: sweet potato adsorbent, heavy metal ion, kinetics, isotherm, sorption, cadmium 
Nomenclature

\begin{tabular}{|c|c|}
\hline $\mathrm{C}_{\mathrm{i}}$ & Initial metal ion concentration $\left(\mathrm{mgl}^{-1}\right)$ \\
\hline $\mathrm{C}_{\mathrm{t}}$ & Metal ion concentration at time $\mathrm{t}\left(\mathrm{mgl}^{-1}\right)$ \\
\hline SEM & Scanning electron microscopy \\
\hline $\mathrm{q}_{\max }$ & Langmuir isotherm maximum adsorption capacity $\left(\mathrm{mgg}^{-1}\right)$ \\
\hline qt & Metal ion loading at time $\mathrm{t}\left(\mathrm{mgg}^{-1}\right)$ \\
\hline $\mathrm{R}_{\mathrm{L}}$ & Langmuir separation factor \\
\hline$r^{2}$ & Co-efficient of determination \\
\hline $\mathrm{t}$ & Contact time \\
\hline $\mathrm{m}$ & Mass of adsorbent \\
\hline $\mathrm{V}$ & Volume of adsorbate \\
\hline PTPS & Sweet potato peel residue \\
\hline $\mathrm{K}_{2}$ & Pseudo-second order rate constant \\
\hline $\mathrm{K}_{\mathrm{id}}$ & Intraparticle diffusion rate constant \\
\hline $\mathrm{Cd}$ & Cadmium \\
\hline $\mathrm{H}$ & Pseudo-second order initial adsorption rate \\
\hline $\mathrm{K}_{1}$ & Pseudo-first order rate constant \\
\hline qe & Equilibrium adsorption loading \\
\hline$x^{2}$ & Chi-square test \\
\hline RMSE & Root mean square error \\
\hline CHNS/O & Carbon, hydrogen, nitrogen, sulphur and oxygen \\
\hline XRF & $\mathrm{X}$-ray fluorescence \\
\hline EDAX & Energy dispersive $\mathrm{X}$-ray analysis \\
\hline pHpzc & $\mathrm{pH}$ point of zero charge \\
\hline $\mathrm{N}$ & Freundlich isotherm parameter \\
\hline $\mathrm{K}_{\mathrm{F}}$ & Freundlich isotherm constant $\left(\mathrm{mgg}^{-1}\right)$ \\
\hline $\mathrm{K}_{\mathrm{L}}$ & Langmuir isotherm constant $\left(\mathrm{lmg}^{-1}\right)$ \\
\hline ATR-FTIR & Attenuated total reflectance Fourier transform infra-red \\
\hline
\end{tabular}




\section{Introduction}

Environmental pollution, food poverty, climate change and fossil fuel depletion are some of the most pressing challenges facing humanity in this century. These issues are generating interest globally as the race to find solutions that will sustain our continued human existence gathers momentum. The development of $21^{\text {st }}$ century solutions to these challenges have also brought about pollution incidences as environmental pollution is increasing at great proportions due to rapid industrialisation that is expanding to previously less developed Countries and cities. This has resulted in the rapid and indiscriminate use and disposal of resources that pose significant threat to the human and environment such as heavy metals (Jiang et al., 2015). Heavy metal ions are ubiquitous in the environment but their increased levels in air, water and land resources are consequences of man-made activities. One of the most toxic metal ions in our environment that has raised global concern is cadmium and this element together with other heavy metal ions like lead, mercury, and chromium are not only toxic but are non-biodegradable making them able to accumulate and persist in the food chain (Ceribasi and Yetis, 2001).This has led to toxic incidences that have been reported in literature such as the "itai-itai" disease, which arose due to cadmium poisoning in the Jinzu river area of the Toyama prefecture in Japan. The implication of the cadmium toxicity resulted in the softening of bone (osteoporosis) and kidney failure which affected the inhabitants of the area due to the consumption of cadmium contaminated fish (Siswoyo et al., 2014; Giwa et al., 2013).

The pollution of aquatic ecosystems with heavy metal ions such as cadmium is one of the major outlets of metal ion toxicity affecting humans because a large number of number of aquatic resources are used by man for different activities therefore raising the possibility of potential health risk from the contamination of this resource (Hossain et al., 2015). For example wastewater discharges from industrial activities has been reported as one of the main outlets of aquatic pollution from heavy metals. Cadmium can be detected in a number of untreated effluents from a number of processes in the electroplating industry, nickel-cadmium battery manufacture, fertilizer, pesticides, pigments and dyes as well as textile production industries (Salim et al., 1992; Cheung et al., 2000; Perez-Marin et al., 2007). These beneficial uses of cadmium in industrial processes have led to increased cadmium transport within the proximity of man's environment. However, poor environmental practices has led to their introduction into the food web at magnified levels resulting in cadmium interfering with the physiological, behavioural and biochemical processes in man (Prapagdee et al., 2014; 
Bernard, 2008; Johri et al., 2010; Hossain et al., 2015). The significance of this problem has

led to the inclusion of cadmium as one of the priority pollutants that should be eliminated from drinking water and discharged effluents by the United States Environmental Protection Agency (USEPA) and the World Health Organisation (WHO). According to the USEPA the recommended maximum contaminant level (MCL) and maximum contaminant level goal (MCLG) of cadmium in drinking water is $0.005 \mathrm{mgL}^{-1}$ (Meitei and Prasad, 2013; Amouei et $a l ., 2013)$. Hence, there is need to remove this toxic metal ion from aquatic resources to protect our environment as well as flora and fauna.

A number of conventional techniques have been used to remove heavy metal ions such as cadmium from effluents and aqueous systems and these include; coagulation, foam floatation, precipitation, ion exchange, reverse osmosis, solvent extraction, chelation, electrolysis, chemical oxidation and membrane technology (Sen, 2012; Tyowua et al., 2013; Sari and Tuzen, 2009; Meitei and Prasad, 2013; Alimohammadi et al., 2013). These approaches have been reported to either be too expensive for the treatment and disposal of the secondary toxic sludge or ineffective/expensive when heavy metal ions are dissolved in large volumes of solution at relatively low concentrations (Rao et al., 2009; Volesky, 1990; Basso et al., 2002; Saleh, 2010). These limitations have made a lot of focus to turn to the application of adsorption technology for the removal of these metal ions from effluents. Adsorption has a number of advantages such as ease of availability and operation, low cost of operation and the possibility of utilising it in a variety of industrial and domestic wastewater systems. It has also been reported to have the capability to remove complex forms of heavy metals and can be operated over a range of pH (Rao et al., 2010; Prapagdee et al., 2014). Activated carbon is the most common adsorbent used in adsorption applications in many countries but the high cost of activated carbon especially in developing (where industrialization is increasing with high pollution related activities associated with heavy metal ions) has led to the quest for materials that can be used as alternatives to activated carbon that are less expensive and readily available (Mishra and Patel, 2009; Tyowua et al., 2013; Siswoyo et al., 2014; Wasewar et al., 2010).

In response to this, a number of studies have been reported on the use of agricultural residues, waste materials and other low cost non-conventional materials as adsorbents for heavy metal ions. These include; canola residue (Amouei et al., 2013); melon seed husk (Giwa et al., 2013); fluted pumpkin (Horsfall and Spiff, 2005); cassava waste (Abia et al., 2003);groundnut husk (Dubey and Gopal, 2006); maize cob (Igwe and Abia, 2007) and orange waste (Perez- 
Marin et al., 2007); Manihot sculenta cranz waste (Augustine et al., 2007; Abia et al., 2006);

Sweet potato (Ipomoea batatas L.) is a crop that is native to tropical America and its one of the major root and tuber crops in the tropical regions of the world. It is widely grown and consumed as a staple food in many parts of Africa, Latin America, Asia and the Pacific Islands (FAO, 1998). It is the tenth major crop in world with a global output of about 100 million tonnes per year (UNCTAD, 2012). Nigeria is second largest producer after China with a reported annual output of 2.83 million tonnes in 2010 (UNCTAD, 2012) and 3.45 million tonnes in 2013 (FAOSTAT, 2015). In Nigeria, sweet potato is grown for both human and animal consumption and it is consumed in the boiled form after it has been peeled (Olagunju et al., 2013 ; Egbe et al., 2012). The peel has no significant application and is mainly used as animal feed though the generation capacity outstrips animal consumption in many areas of the country thereby leading to a waste management problem.

Activated carbon has been used for treatment of municipal and industrial wastewaters in many countries and has developed rapidly on a much larger scale than ever before. However, the deployment of activated carbon produced from developed countries in the treatment of wastewaters in developing countries has significant financial implications and this has limited their use especially in small scale industries in developing countries where cost of wastewater treatment plays a fundamental role in the decisions of whether the process is carried out or not. Due to this constraint, the utilisation of readily available materials like agricultural residues in these developing countries has become the focus of research for use in wastewater treatment. The novelty of this work is based on the potential of using of a waste material to treat heavy metal effluents at a low cost that will make the remediation of wastewater in the developing countries more viable and environmentally friendly. Based on the aforementioned waste challenge posed by this food crop, the present study examines the potential of using this common agricultural residue in Nigeria as an adsorbent for the removal of $\mathrm{Cd}$ (II) ions from 
aqueous solution. Consideration was also given to the examination of the influence some parameters such as $\mathrm{pH}$, contact time and initial concentration of $\mathrm{Cd}$ (II) ion on the sorption process. Physical and chemical characterisation of the sweet potato peel agricultural residue was also carried out to determine its intrinsic characteristics and their effect on sorption.

\section{Materials and methods}

\subsection{Chemicals and adsorbent preparation}

A standard stock solution of $1000 \mathrm{mgL}^{-1}$ of $\mathrm{Cd}(\mathrm{II})$ ion was prepared by dissolving an appropriate amount of analytical grade reagent [cadmium nitrate tetrahydrate- $\mathrm{Cd}\left(\mathrm{NO}_{3}\right)_{2} .4 \mathrm{H}_{2} \mathrm{O}$ (Sigma-Aldrich) (99\% assay)] in deionised water using a $1000 \mathrm{ml}$ volumetric flask $( \pm 0.8 \mathrm{ml}$ MBL Boro England). The stock solution was acidified to prevent hydrolysis by adding $5 \mathrm{ml}$ $\mathrm{HNO}_{3}$ and the volume was made up to the $1000 \mathrm{ml}$ mark. The content of each volumetric flask was agitated in a Heidolph Unimax instrument 1010 shaker at $300 \mathrm{rpm}$ for $3 \mathrm{~h}$ to ensure complete dissolution at room temperature $\left(25^{\circ} \mathrm{C}\right)$. Potato peels were obtained from an agricultural farm in Uyo, Akwa Ibom in Nigeria. The peels were washed with hot deionized water to remove dirt and colour and oven dried at $110^{\circ} \mathrm{C}$ for 24 hours. The dried residue was thereafter pulverized using a Coors porcelain mortar and pestle. Particle size separation of the residues was carried out by sequential sieving wherein $500 \mathrm{~g}$ of the pulverized residue was sieved using a laboratory test sieve shaker model E.V.L.1. (Endecott's Limited London). After the sieving, the residues in the $140 \mu \mathrm{m}$ sieve tray were taken off and put in new and clean polypropylene bottles and labelled unmodified residues and stored at room temperature for further use in the adsorption studies. This sample was labelled as the unmodified Sweet potato peel residue (PTPS) and used for Cd(II) ion sorption studies.

\subsection{Adsorbent Characterisation}

Characterisation of the physical and chemical properties of the PTPS residue adsorbent was carried out using a number of techniques which are subsequently described in this study.

\subsubsection{Fourier-Transform infra-red spectroscopy -FTIR}

Fourier transform infra-red spectroscopy was used to evaluate the functional groups in the PTPS adsorbent. Prior to the analysis, the adsorbent was dried in an air oven for $24 \mathrm{~h}$ at $110^{\circ} \mathrm{C}$ 
to remove the moisture contents of the sample. This was to eliminate any interference in the Avatar 360 FT-IR with ATR probe. The spectra range was from $4000-400 \mathrm{~cm}^{-1}$ and the spectra were collected using the FTIR-ATR spectrometer using a total average of 32 coadded scans and a spectral resolution of $4 \mathrm{~cm}^{-1}$ with background subtraction. All the measurements were performed at room temperature and the spectra were recorded using transmittance mode.

\subsubsection{Elemental composition analysis-CHNS/XRF}

The carbon, hydrogen, nitrogen and oxygen content of the PTPS adsorbent were determined using a Flash 2000 CHNS/O automatic elemental analyser (Thermo Fisher Scientific). The sample was weighed and the weight recorded and the samples were then put into tin capsules and placed inside the Thermo-Fisher MAS 200R auto-sampler for analysis. After analysis, the $\mathrm{C}, \mathrm{H}, \mathrm{S}$ and $\mathrm{N}$ content of the PTPS adsorbent was calculated by the instrument and the oxygen content was determined by difference. X-ray fluorescence spectroscopy was also used to determine the inorganic composition of the PTPS adsorbent. The XRF instrument used was a wave-length dispersive XRF (WDXRF) model AXIOS (PANalytical). Samples were pelletized to $6 \mathrm{~mm}$ masks using wax as binder with a powder to wax ratio of $10 \mathrm{~g}$ to $3 \mathrm{~g}$ and analysed to determine the chemical composition of the PTPS adsorbent.

\subsubsection{SEM and EDAX Analysis}

The surface morphology of the PTPS adsorbent before and after Cd(II) ion adsorption as well as the chemical composition were analysed by scanning electron microscopy (SEM) and energy dispersive X-ray analysis (EDAX) respectively. The equipment used for the SEM and EDAX analysis was a FEI Quanta 200 Environmental Scanning Electron Microscope. The PTPS adsorbent was placed and pressed onto a carbon tab (Agar Scientific) and mounted on a 0.5 " SEM pin stubs (Agar Scientific). The samples were preconditioned for analysis by coating using an EMITECH K550X sputter gold coater and coating was carried out for 15 minutes and thereafter analysed in the vacuum chamber at $30 . \mathrm{kV}$ and 0.75 Torr. 


\subsubsection{BET surface area, porosity and density analysis}

The surface area and porosity of the PTPS adsorbent was determined using a Micromeritics Tristar 3000 Surface Area and Porosity Analyzer. The PTPS adsorbent was pre-conditioned by drying in an oven for $24 \mathrm{~h}$ at $110^{\circ} \mathrm{C}$ after which $1.033 \mathrm{~g}$ was weighed into the BET sample tube and conditioned (degassed) for $21 \mathrm{hr}$ at $200^{\circ} \mathrm{C}$ under nitrogen flow in order to eliminate moisture and other gases on the adsorbent using the Micromeritics Flow prep 060 sample degas system. Thereafter it was cooled under nitrogen flow for $5 \mathrm{mins}$ in the cooling section of the Flow prep system and when it had cooled it was then weighed again to determine the actual weight of sample to be analysed. The sample (inside) the BET tube was thereafter exposed to nitrogen at $77 \mathrm{~K}$, whereby the gas pressure in the tube with the sample was allowed to reach equilibrium before subsequent dosing where a series of successive incremental pressures of nitrogen doses were done in order to obtain an adsorption isotherm. The density of the PTPS adsorbent was determined using helium pycnometry. The instrument used for the analysis of the residues was the Accu Pyc 111340 Helium pycnometer manufactured by Micromeritics. A weighed amount of sample to be analysed was dried in an oven for $24 \mathrm{~h}$ before analysis. Pressure and volume calibration of instrument was first carried out before analysis of the samples. The calibration standard was placed in the propylene cup. Thereafter the two bulbs were put into the cup gently and the instrument calibrated. The weighed sample was then placed into the propylene cup and the analysis using helium gas was carried out at 5 purges and 5 cycles.

\subsection{5 pH point of zero charge (pHpzc) determination}

The point of zero charge (pHpzc) of the PTPS adsorbent was determined using a Malvern Zetasizer 3000 HSA (Malvern Instruments). The PTPS adsorbents were prepared by weighing $0.1 \mathrm{~g}$ of sample into $20 \mathrm{ml}$ of $0.01 \mathrm{M} \mathrm{NaCl}$ solution at $\mathrm{pH}$ range of $2-12$ and agitating it at $300 \mathrm{rpm}$ in a shaker for $24 \mathrm{~h}$. After which it was filtered and $10 \mathrm{ml}$ of each of sample was taken into labelled polypropylene bottles for analysis. The Zetasizer syringe was cleaned and the analysis cell purged with deionized water using the syringe. The samples of each of the adsorbents at different $\mathrm{pH}$ were inserted into the Zetasizer electrophoresis cell (a $3 \mathrm{ml}$ polystyrene curvette with a light path of $10 \mathrm{~mm}$ ) using a syringe. The zeta potential at each $\mathrm{pH}$ was measured and recorded. Three measurements were carried out and an average zeta potential for each adsorbent suspension at the different $\mathrm{pH}$ values were recorded. 


\subsubsection{Thermogravimetric analysis}

The Thermogravimetric analyzer (TGA) used in the analysis of the PTPS adsorbent was the TGA Q5000 (TA instrument). 28.25mg of the sample was weighed onto a ceramic pan and subjected to temperature profile analysis from $20^{\circ} \mathrm{C}$ to $500^{\circ} \mathrm{C}$ under nitrogen atmosphere to monitor the thermal degradation at a heating rate of $10{ }^{\circ} \mathrm{C} \min ^{-1}$. The nitrogen flow rate was maintained at $50 \mathrm{ml} \mathrm{min}{ }^{-1}$ and the temperature was equilibrated at $25^{\circ} \mathrm{C}$ and maintained for 5 minutes. Thereafter it was increased to $100{ }^{\circ} \mathrm{C}$ at a rate of $10{ }^{\circ} \mathrm{C} \mathrm{min}^{-1}$ and maintained for 60 minutes. After this time interval it was ramped at $10{ }^{\circ} \mathrm{C} \min ^{-1}$ up to $500{ }^{\circ} \mathrm{C}$ and maintained for 60 minutes. Subsequently, air was selected to burn off the residue at a flow rate of $50 \mathrm{ml} \mathrm{min}{ }^{-1}$ up to $600^{\circ} \mathrm{C}$ for 30 minutes. The thermal degradation profile of the sample gives information on the weight loss $(\%)$ with temperature and time using a single thermogravimetric curve. From the TG profile, information of the different components of the sample like the moisture content, volatile content, fixed carbon and ash composition were obtained using the TA Instruments Universal Analysis 2000 software.

\subsection{Batch sorption experiments}

Standard stock solution of $1000 \mathrm{mgl}^{-1}$ of $\mathrm{Cd}(\mathrm{II})$ ion from the reagent- cadmium nitrate tetra hydrate-Cd $\left(\mathrm{NO}_{3}\right)_{2} .4 \mathrm{H}_{2} \mathrm{O}$ (Sigma-Aldrich) (99\% assay) was prepared by dissolving stoichiometric amounts of the analytical grade reagent in deionised water using a $1000 \mathrm{ml}$ volumetric flask. The working solutions for individual sorption experiments were prepared by serial dilution of aliquots of the stock solution. Batch sorption experiments for the equilibrium adsorption experiments were carried out by agitating known weights (2.0g) of the PTPS adsorbents with $100 \mathrm{ml}$ of adsorbate solutions of different initial concentrations $(50,100,150$, 200, 250, 300, 350, 400, 450 and $500 \mathrm{mgl}^{-1}$ ). The $\mathrm{pH} 6.5$ and a contact time of 180 minutes were used for the adsorption studies for initial concentration studies, while 1440 minutes was used for the contact time studies. The $\mathrm{pH}$ for each experiment was modified using $\mathrm{NaOH}$ and $\mathrm{HCl}$. For the study of the effect of adsorbate $\mathrm{pH}$ on the removal of Cd(II) PTPS) the range of $\mathrm{pH}$ was from $2-10$, while the other parameters used were: initial metal ion concentration of $500 \mathrm{mgl}^{-1}$, temperature of $25^{\circ} \mathrm{C} \pm 0.5$ and a reaction volume of $0.1 \mathrm{~L}$. The amount of adsorbent used was $2.0 \mathrm{~g}$ and $\mathrm{HCl}$ and $\mathrm{NaOH}$ were used to vary the different adsorbate $\mathrm{pH}$. The effect of contact time on the sorption processes was studied using 5 minutes to $72 \mathrm{~h}$ (1440min) intervals. The reaction vessel for each adsorption experiment was a $250 \mathrm{ml}$ conical flask and the sorption was carried out at a laboratory temperature of $25^{\circ} \mathrm{C} \pm 0.5$. Each conical flask with 
the adsorbate and adsorbent was agitated for a specified contact time in a Heidolph MR 3001 magnetic stirrer with speed and temperature controls at a speed of $200 \mathrm{rpm}$. At the end of each experiment, the resulting solution was separated from the adsorbent. The metal ion concentrations of the adsorbate solution were determined spectrophotometrically using ICPOES. For the determination of metal ion loading after sorption, the amount of metal ion adsorbed (qe) was calculated using eqn. (1).

$$
q_{e}=\frac{(C i-C t) V}{w}
$$

Where $\mathrm{C}_{\mathrm{t}}\left(\mathrm{mgl}^{-1}\right)$ is the metal ion concentration at time $\mathrm{t}$, qe $\left(\mathrm{mgg}^{-1}\right)$ is the loading of the metal ion at time $\mathrm{t}, \mathrm{C}_{\mathrm{i}}$ is the initial metal ion concentration, $\mathrm{w}$ is the weight of the adsorbent $(\mathrm{g})$ and $\mathrm{V}$ is the volume of the aqueous system.

\subsubsection{Data quality evaluation}

All adsorption experiments were carried out in triplicates to ensure reproducibility and accuracy of results. The relative standard deviation was used as the error parameter for all analysis and the value for each set of measurements was $<5 \%$. Each experimental set was carried out using blanks to ensure the elimination of errors associated with experimental conditions. For each experimental analysis procedure, blanks were prepared using deionized $\mathrm{H}_{2} \mathrm{O}$ and the blank samples were subjected to the same treatment process using the same type of experimental vessel. In the analysis of Cd(II) metal ion in solution, the blank samples were also analysed first in the Inductively coupled plasma optical emission spectrometer (ICPOES)-Vista-MPX instrument prior to analysis of the standards and the samples. The metal ion concentration in the stock solution and prepared aqueous solution before adsorption were also analysed to ensure the correct concentration was prepared and used for adsorption. The instrument was programmed to take into account any blank concentration and the actual metal ion concentration of $\mathrm{Cd}(\mathrm{II})$ ion.

\section{Results and Discussions}

\subsection{Adsorbent characterisation}

The physical and chemical characteristics of the PTPS adsorbent are presented in Table 1. The ultimate and proximate analysis of the adsorbent indicates that it is mainly organic in nature 
with some inorganic constituents as shown by the ash content. The organic content (carbon, nitrogen hydrogen and oxygen) of the PTPS residue adsorbent is consistent with what has been reported in literature for other types of dried biomass (Chang et al., 2015). The ash content was determined by two methods- using thermogravimetric analyser and using the procedure described in AOAC (2000) in which $1 \mathrm{~g}$ of the adsorbent was carbonised at $600^{\circ} \mathrm{C}$ for $6 \mathrm{~h}$ and the weight difference determined as a percentage. The two values obtained from these different methods are shown in Table 1 and are comparable; it indicates that the PTPS adsorbent had a high percentage of ash that is due to its inorganic composition.

Table 1: Physical and chemical characteristics of PTPS adsorbent

\begin{tabular}{|c|c|}
\hline Characteristics & PTPS \\
\hline \multicolumn{2}{|l|}{ Ultimate Analysis (wt\%) ${ }^{\mathrm{a}}$} \\
\hline Carbon & 40.1 \\
\hline Hydrogen & 5.87 \\
\hline Nitrogen & 1.66 \\
\hline Oxygen $^{c}$ & 46.3 \\
\hline Sulphur & 0.30 \\
\hline \multicolumn{2}{|l|}{ Proximate Analysis (wt\%) ${ }^{b}$} \\
\hline Fixed carbon & 20.5 \\
\hline Volatile matter & 62.4 \\
\hline Moisture & 4.90 \\
\hline Ash & 11.2 \\
\hline $\mathrm{Ph}$ & 5.70 \\
\hline pHpzc & 6.30 \\
\hline BET surface area $\left(\mathrm{m}^{2} \mathrm{~g}^{-1}\right)$ & 1.91 \\
\hline Total pore volume $\left(\mathrm{cm}^{3} \mathrm{~g}^{-1}\right)$ & $4.87 \times 10^{-3}$ \\
\hline BJH desorption average pore diameter $(\mathrm{nm})$ & 22.3 \\
\hline Ash content $(\%)^{d}$ & 10.6 \\
\hline Helium density & 1.51 \\
\hline \multicolumn{2}{|l|}{${ }^{\mathrm{a} U l t i m a t e}$ analysis using CHNS analyser } \\
\hline \multicolumn{2}{|c|}{${ }^{\mathrm{b}}$ Proximate analysis using thermogravimetric analyser } \\
\hline \multicolumn{2}{|l|}{${ }^{\circ}$ Obtained by difference } \\
\hline${ }^{\mathrm{d} U s i n g}$ AOAC (2000) method & \\
\hline
\end{tabular}


The ash content of agricultural residues is an important parameter in the adsorption studies as or are transformed via thermochemical methods into other types of adsorbents as these can aid heavy metal removal via ion-exchange processes (Sardella et al., 2015). The composition of the PTPS adsorbent is similar to what has been reported for some lignocellulosic adsorbents obtained in Nigeria such as coconut husk (Cocos nucifera), cocoa pods (Theobroma cacao), kola nut pods (Cola nitida) and plantain peels (Plantago major) (Oladayo, 2010). The ash content and moisture content of these residues reported by Oladayo (2010) were; 3.95, 12.67, 7.76 and 6.06 (\% ash content) and 5.34, 10.04, 11.99 and 8.71(\% moisture) for coconut husk, cocoa pods, kola nut pods and plantain peels respectively. Also the moisture content, ash content and pHpzc of the PTPS adsorbent are similar to those reported by Pandey et al., (2015) for Kush grass and bamboo leaves adsorbents. The PTPS adsorbent has a high volatile matter content which is characteristics of the organic nature of the lignocellulosic biomass which contains cellulose, lignin and hemicellulose (Khor et al., 2009). Odetoye et al., (2014) in their study on the thermochemical characterisation of Parinari polyandra Benth fruit shell reported a 78\% volatile matter content for this biomass thus indicating its high organic matter content compared to that of the PTPS residue adsorbent.

The density of the PTPS adsorbent was also determined as described in the materials and methods section. Adsorbents with high solid density are desirable for industrial applications to ensure high structural strength in water treatment processes and the density of porous materials is also an important parameter in the study of the structure and properties of adsorbents (Malbrunot et al., 1997; Guo and Lua, 2002). The helium density of the PTPS residue obtained based on the helium pycnometry method is presented in Table 1 . The value obtained (1.51) indicates that the adsorbent had a low solid density meaning that its mechanical or structural strength is poor. The density of residues also has implications on the mechanical strength of adsorbents prepared from them especially those of activated carbon adsorbents (Guo and Lua, 2000; Wan et al., 2014).

The $\mathrm{pH}$ is an important variable in the adsorption process involving metal ions as it can influence the type of speciation, degree of ionization of adsorbate and the nature of functional groups on the surface of an adsorbent (Sardella et al., 2015). The effect of $\mathrm{pH}$ of the adsorbent and the solution on the adsorption process can be studied using a plot of the zeta potential against the $\mathrm{pH}$ to determine the $\mathrm{pH}$ at which the charge on the surface is zero ( $\mathrm{pHpzc}$ ) (Gautam et al., 2014). This is an important parameter as it gives information on the $\mathrm{pH}$ that 
can be used for adsorption of cations and anions; due to the understanding of the regions within the $\mathrm{pH}$ window that is dominated with basic or acidic functional groups (Fernandez et $a l ., 2015)$. The $\mathrm{pH}$ of the PTPS was 5.70 and the $\mathrm{pH}$ point of zero charge was 6.32 as shown in Table 1. From the value of the $\mathrm{pH}$ and $\mathrm{pHpzc}$ of the adsorbent, it was observed that the adsorbent was mainly acidic in nature and the $\mathrm{pH}$ of 6.5 was chosen for the adsorption studies as the target ions was positive, hence a $\mathrm{pH}$ that is above the pHpzc has to be chosen to facilitate the adsorption of the positive Cd(II) by the PTPS adsorbent.

\subsubsection{BET Surface area and porosity}

The Brunauer-Emmett-Teller (BET) surface area and pore characteristics of the PTPS adsorbent obtained using Nitrogen adsorption-desorption shown in Figure 1 are presented in Table 1. The result shows that the surface area of the PTPS adsorbent was $1.91 \mathrm{~m}^{2} \mathrm{~g}^{-1}$. This indicates that the PTPS adsorbent did have a low surface area and this is similar to what has been reported in previous studies for some agricultural residues. These lignocellulosic residues are known to have low surface areas due to the nature of the cellulose, hemicellulose and lignin content in them. These results in these residues having wide pore size distributions due to the high percentage of mesopores/macropores within their network compared to micropores as can be observed in the pore size distribution in Fig.1. Furthermore, these wide pore size distributions of mesopores/macropores in the lignocellulosic materials make them suitable for liquid phase sorption as it facilitates diffusion of the adsorbate into the adsorbent structure (Ribeiro et al., 2015; Menendez-Diaz and Martin-Gullon, 2006). However, it should be noted that the sorption properties of these residues are not only dependent on the possession of large surface areas as since porosity alone is not the only criteria required for good adsorbents. In addition to porosity, the nature and types of functional groups on these materials which serve as active sites for sorption contributes significantly to their adsorption potential for target pollutants (organic or inorganic). Thus, lignocellulosic residues have been reported to possess a number of different functional groups on their surface such as phenolic, carboxylic, hydroxyl, amines and ether groups which act as sources of physical and chemical interactions that facilitates adsorption via a number of mechanisms that include; hydrogen bonding, electrostatic interactions and surface complexation (Tan et al., 2015; Nguyen et al., 2013; Barkar et al., 2013; Bailey et al., 1999). Martin-Lara et al., (2013) in their study on the development and characterisation of biosorbents to remove heavy metals from aqueous solutions by chemical treatment of Olive stone observed that the Olive stone residue had a 
BET surface area of $0.163 \mathrm{~m}^{2} \mathrm{~g}^{-1}$ and a $\mathrm{Pb}^{2+}$ loading capacity of $6.32 \mathrm{mgg}^{-1}$, thereby indicating that surface area alone is not the only indicator of a good adsorbent.

Furthermore, Wan et al., (2014) have reported the BET surface area of $0.86 \mathrm{~m}^{2} \mathrm{~g}^{-1}$ for tea waste adsorbent used for the sorption of lead (II), cadmium (II) and copper (II) ions from aqueous solution. The surface area of meranti sawdust reported by Rafatullah et al., (2009) in their study was $0.62 \mathrm{~m}^{2} \mathrm{~g}^{-1}$. Lacerda et al., (2015) has also reported on the BET surface areas of some lignocellulosic biomass, in their study the surface area obtained for the residues were; $0.85 \mathrm{~m}^{2} \mathrm{~g}^{-1}$ (carnauba palm leaves); $0.60 \mathrm{~m}^{2} \mathrm{~g}^{-1}$ (macauba seed endocarp) and $0.86 \mathrm{~m}^{2} \mathrm{~g}^{-1}$ (pine nut shell). The Nitrogen adsorption-desorption isotherm has been classified according to the Brunauer, Deming, Deming and Teller (BDDT) method (Sing, 1982; Sing, 2001) and based on this approach the nitrogen isotherm plot for the PTPS adsorbent is classified as a type II isotherm, which describes nonporous materials or those with macropores/open voids (Tsai et al., 2006).

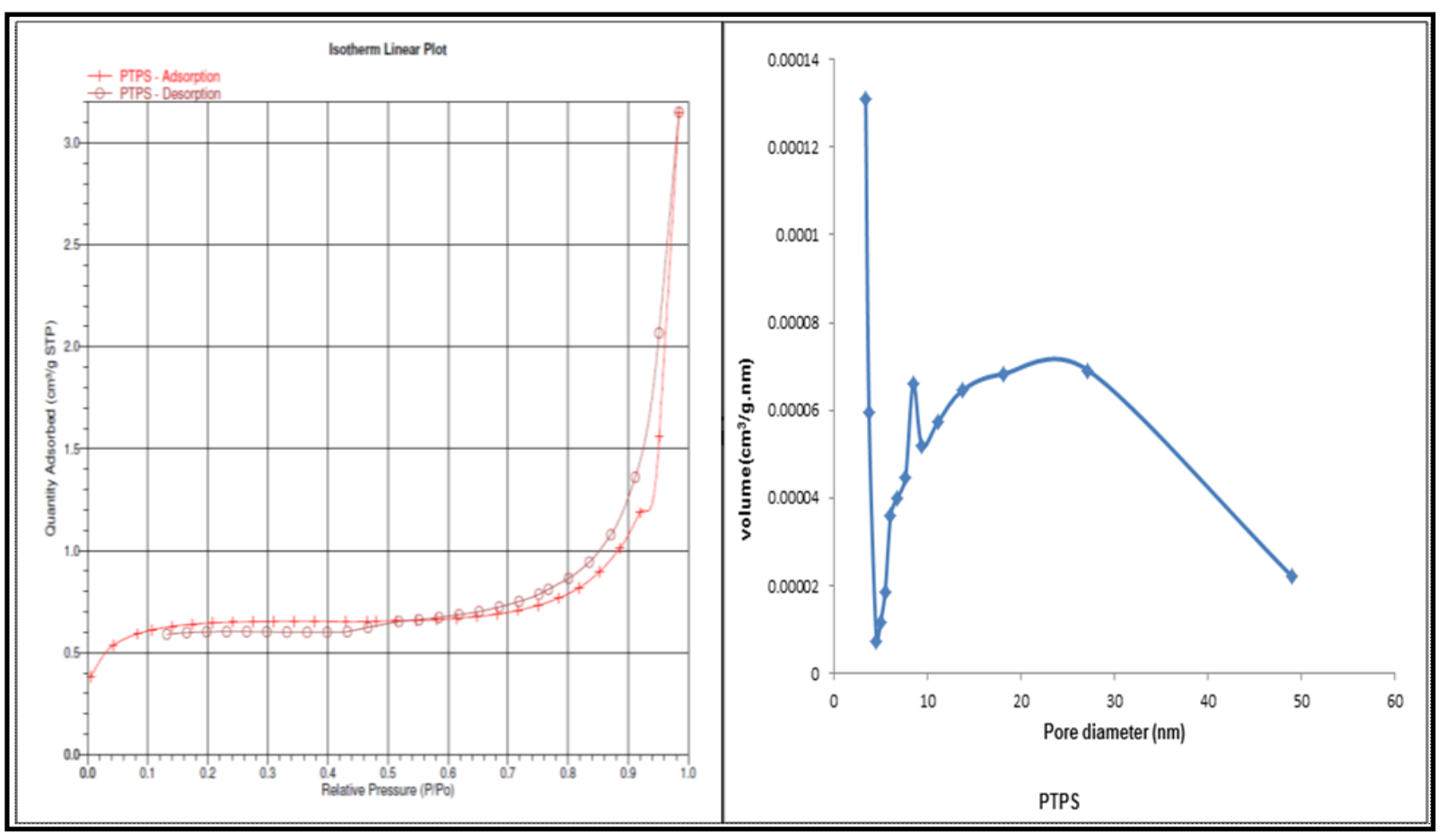

Figure 1: $\mathrm{N}_{2}$ adsorption-desorption isotherm and pore size plot of PTPS residue adsorbent

The total pore volume of the PTPS residue adsorbent is $4.87 \times 10^{-3} \mathrm{~cm}^{3} \mathrm{~g}^{-1}$ as presented in Table 1 and this indicates that the volume of pores is small. The small pore volume of the PTPS residue may be due to the nature of arrangement of cellulose, hemicellulose and lignin structures within the lignocellulosic framework of the material which may lead to the development of few number pores or blocked pores if they exist (Bota et al., 1996). This 
observation is similar what has been reported in previous studies for lignocellulosic residues.

Lacerda et al., (2015) has reported on the total pore volume of some lignocellulosic biomass and in their study the total pore volumes obtained for the residues were; $3.59 \times 10^{-4} \mathrm{~cm}^{3} \mathrm{~g}^{-1}$ (carnauba palm leaves); $2.01 \times 10^{-3} \mathrm{~cm}^{3} \mathrm{~g}^{-1}$ (macauba seed endocarp) and $3.16 \times 10^{-3} \mathrm{~cm}^{3} \mathrm{~g}^{-1}$ (pine nut shell). The average pore diameter of the PTPS adsorbent based on an analysis of the desorption branch of the $\mathrm{N}_{2}$ adsorption-desorption isotherm plot (Figure 1) was $22.3 \mathrm{~nm}$ indicating that the adsorbent is mesoporous according to the IUPAC classification of porous materials (Sing, 1982, Sing 2001). The pore diameter plot of the PTPS adsorbent is shown in Figure 1 and the nature of the plot indicates that the adsorbent had a trimodal pore size distribution with peaks at 2-30nm.

\subsubsection{Adsorbent Morphology}

Photographs of the raw potato peel and that of the pulverised and dried PTPS adsorbent are shown in Figure 2 and the images indicate a slight colour change after the drying and pulverising of the residue. This may be due to the elimination of some tannin components on the adsorbent surface during the pre-treatment process (Ojedokun and Bello, 2015). The surface characteristics of the PTPS adsorbent were further examined using scanning electron microscopy. The SEM micrograph of the PTPS adsorbent is shown in Figure 3a. The figure indicates the presence of rough crevices on the adsorbent which can be presumed to play a major role in the transport of the Cd(II) ions during sorption (Wahab et al., 2012).

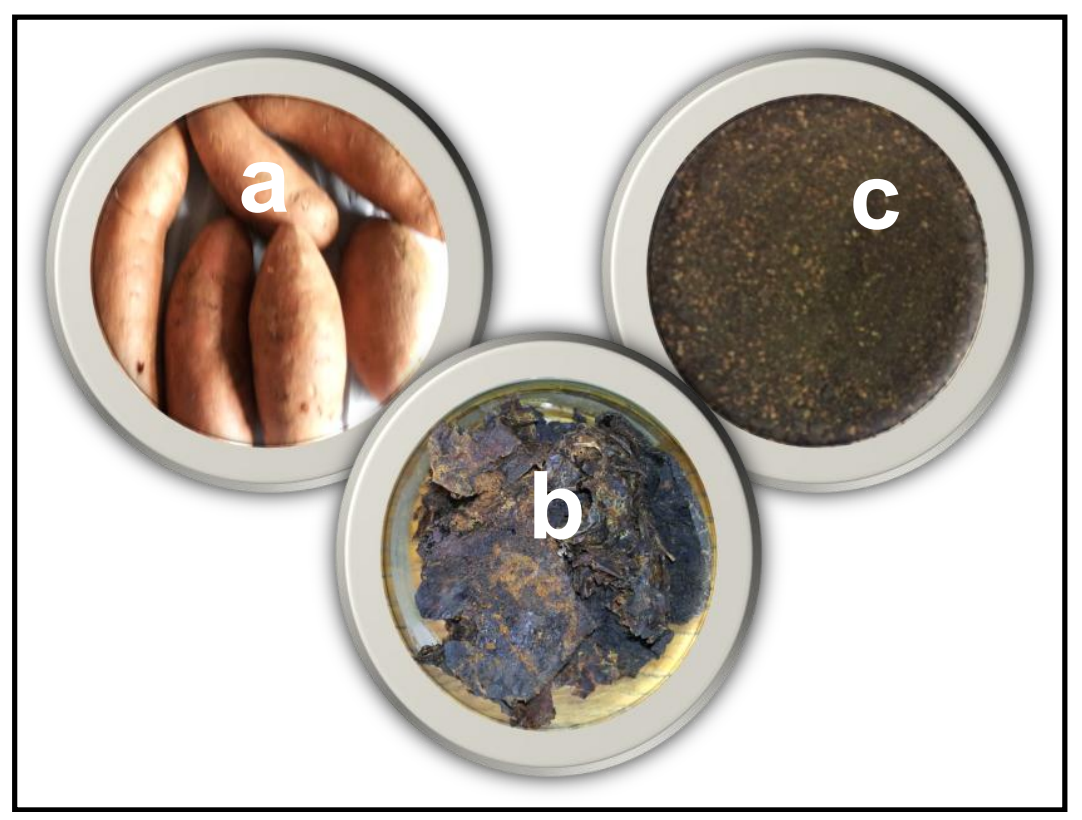

Figure 2: Photograph of sweet potato (a) dried sweet potato peel (b) and pulverised sweet potato residue adsorbent-PTPS (c). 


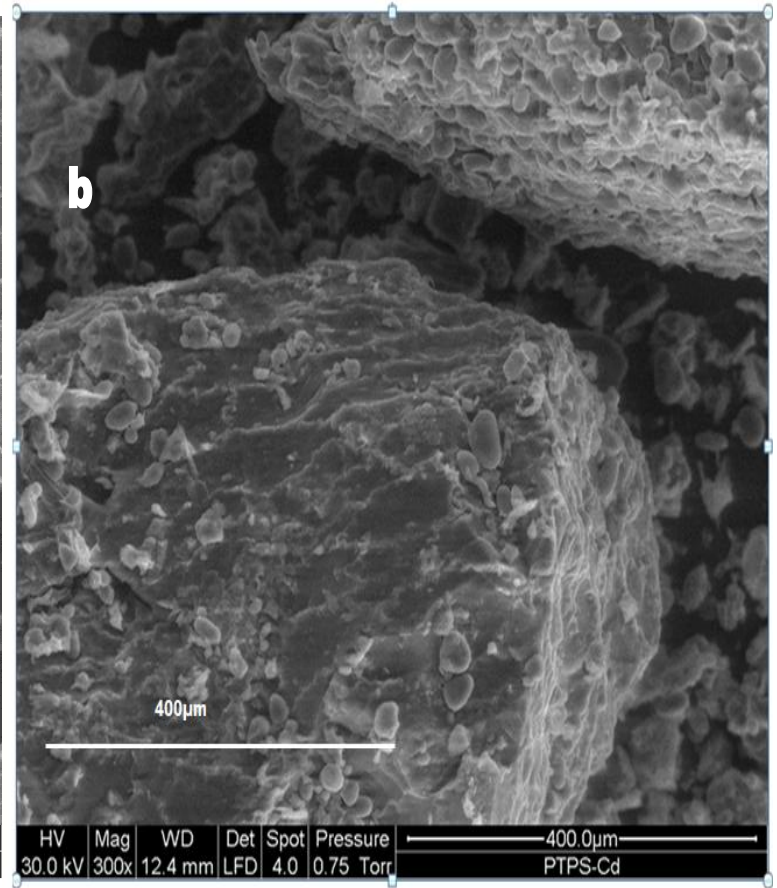

Figure 3: Electron micrograph of PTPS adsorbent (a), PTPS after Cd(II) sorption (b)

It can also be observed from Figure 3a, that there are no well-defined pore structures on the residue surface thereby indicating that the PTPS adsorbent does not have porosity (Tsai et al., 2006). This observation also confirms the inference made from the results of the surface area characterisation of the adsorbent using the shape of the nitrogen adsorption-desorption isotherm. The morphology of the PTPS adsorbent was further examined after $\mathrm{Cd}(\mathrm{II})$ ion sorption and the electron micrograph is shown in Figure 3b. An examination of this image indicates that the morphology of the PTPS adsorbent was not altered after metal ion sorption. However, the surface roughness seen in the SEM of the PTPS adsorbent (Figure 3a) was reduced on the PTPS-Cd adsorbent (Figure 3b). This may be associated with the effect of the impregnation of the $\mathrm{Cd}(\mathrm{II})$ ions on the PTPS adsorbent surface during sorption.

\subsubsection{Chemical composition of adsorbent}

The chemical composition of the PTPS adsorbent was determined using a number of techniques; the carbon, hydrogen, nitrogen, sulphur and oxygen content were determined using the CHNS elemental analyser (oxygen content obtained by difference) (Table 1), while the inorganic content were determined using X-ray fluorescence spectrometry (XRF) and the results are shown in Table 2. In addition the semi-qualitative chemical composition of the PTPS adsorbent was also obtained using energy dispersive X-ray analysis (EDAX) which is 
coupled to the scanning electron microscope (SEM) used for examination of the morphology

Table 2: XRF of PTPS residue adsorbent

$\begin{array}{lllllllllll}\text { Element (\%) } & \mathrm{Na}_{2} \mathrm{O} & \mathrm{MgO} & \mathrm{Al}_{2} \mathrm{O}_{3} & \mathrm{SiO}_{2} & \mathrm{P}_{2} \mathrm{O}_{5} & \mathrm{SO}_{3} & \mathrm{Cl} & \mathrm{K}_{2} \mathrm{O} & \mathrm{CaO} & \mathrm{Fe}_{2} \mathrm{O}_{3} \\ & & & & & & & & & & \\ \text { PTPS } & 0.05 & 0.22 & 0.32 & 1.32 & 0.40 & 0.30 & 0.39 & 2.65 & 0.16 & 0.12\end{array}$

From the analysis, the chemical composition of the residues indicates that carbon, oxygen and inorganic compounds were the main chemical species present in the residue as this is a lignocellulosic material of plant origin. The percentage carbon, hydrogen, nitrogen, oxygen and sulphur content of the PTPS adsorbent is similar to what has been also been reported by Odetoye et al., (2014) in their study on the thermochemical characterisation of Parinari polyandra Benth fruit shell. In their study the percentage carbon, hydrogen, nitrogen, oxygen and sulphur content of the agricultural biomass was $48.045 .76,2.13,43.5$ and 0.10 respectively. The oxygen and carbon content of plant based residues are the main contributors to their high volatile content.

$\mathrm{X}$-ray fluorescence was used to obtain information on the inorganic chemical composition of the PTPS adsorbent considering its high ash content ( $\geq 10 \%$ of the residue). The X-ray fluorescence (XRF) analysis is shown in Table 2 and it can be observed that the composition of the PTPS residue adsorbent is represented as oxides. It can also be inferred from the table, that the amount of silicon and potassium in the PTPS residue were significant $\left[\mathrm{K}_{2} \mathrm{O}(2.65 \%)\right.$ and $\left.\mathrm{SiO}_{2}(1.32 \%)\right]$ compared to those of the other inorganic constituents. The other species that also had considerable composition in the adsorbent were magnesium, phosphorus, aluminium and chloride. The elemental composition of the PTPS residue adsorbent is similar to what has been reported in literature for biomass adsorbents. The sodium and magnesium content in the PTPS residue was higher than that of the rice husk adsorbent reported by Zhang et al., (2014) for $\mathrm{Cu}$ (II) adsorption. However, the percentage silica content of the rice husk (15) was higher than that of the PTPS residue adsorbent. The presence of these inorganic elements in the adsorbent also confirms the high ash content of the PTPS adsorbent and may 
contribute to the type of mechanism for cadmium (II) ion removal onto the adsorbent such as ion-exchange or complexation.

\subsubsection{Energy dispersive X-ray analysis (EDAX)}

The presence of chemical elements in an adsorbent and their relative compositions can also be determined using the energy dispersive X-ray coupled on the SEM instrument. The EDAX was carried out as a spot size analysis wherein the spot of interest was examined for chemical information. The EDAX spectrum and the relative elemental composition of the PTPS adsorbent are presented in Figure 4. From the Figure, the chemical composition of the PTPS residue adsorbent indicates that carbon, oxygen and inorganic compounds were present in the residue. Some of these inorganic compounds include magnesium, aluminium, silicon, phosphorus, sulphur, chloride, potassium, calcium and iron. From the EDAX spectrum, it can be observed that amongst the inorganic elements potassium and silicon were the most abundant in the PTPS residue adsorbent. This trend was also observed from the X-ray fluorescence data previously discussed (Table 2).

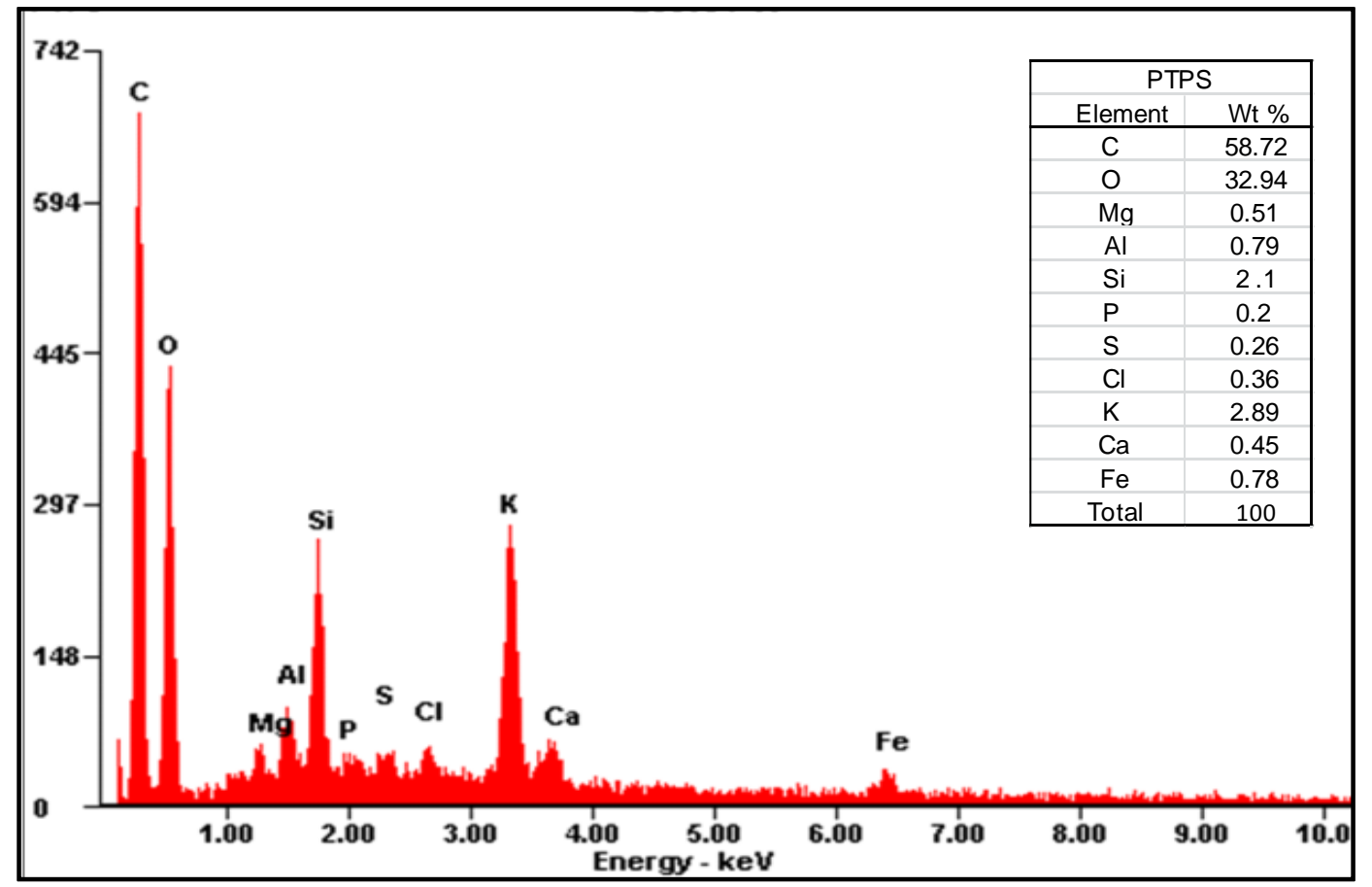

Figure 4: EDAX spectrum of PTPS residue adsorbent 


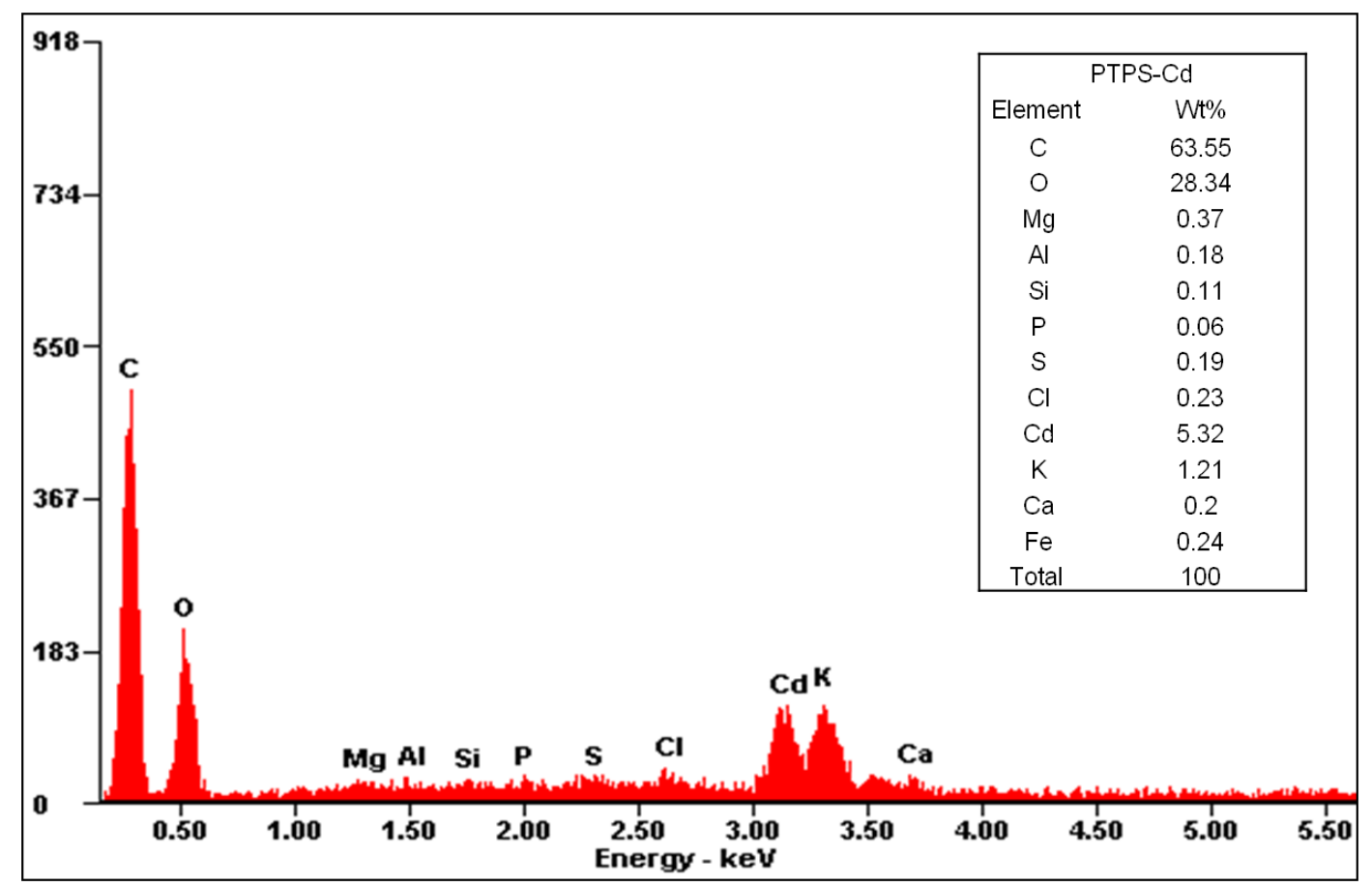

Figure 5: EDAX spectrum of PTPS residue after Cd(II) adsorption

The PTPS residue used for adsorption of Cd(II) was further subjected to EDAX analysis to confirm the presence of the adsorbed $\mathrm{Cd}(\mathrm{II})$ ions and is presented in Figure 5. An examination of the EDAX spectra after Cd(II) ion sorption (Figure 5) indicates that the PTPS residue adsorbent had the characteristic peak associated with $\mathrm{Cd}(\mathrm{II})$ ions thus confirming the possibility that $\mathrm{Cd}(\mathrm{II})$ metal ion sorption had occurred on the surface of these residue adsorbents. This identification of adsorbed metal ion on an adsorbent after sorption using EDAX has been used to confirm the mechanism of metal ion sorption. Iqbal et al., (2009) reports on the use of the EDAX analysis of grapefruit peel to confirm the mechanism of ionexchange for the removal of $\mathrm{Zn}$ (II) from aqueous solutions. The report also noted that the calcium and potassium ions identified in the EDAX spectrum of the fresh grapefruit peel were absent in the peel used for $\mathrm{Zn}(\mathrm{II})$ ion adsorption, thus suggesting that these ions may be involved in the ion-exchange with the $\mathrm{Zn}$ (II) ions. From the results of the EDAX analysis of the PTPS adsorbent it is observed that the spectrum shows a reduction in the amount of divalent elements such as magnesium and calcium ions on the PTPS adsorbent after sorption (Figure 5) when compared to that of the fresh adsorbent (Figure 4). This may suggest that one of the mechanisms of $\mathrm{Cd}(\mathrm{II})$ ion uptake from the aqueous metal ion solution onto the adsorbent surface is via ion-exchange between these divalent metal ions on the PTPS surface and the $\mathrm{Cd}(\mathrm{II})$ ions in the adsorbate. This assumption is similar to what was observed by Iqbal et al., (2009). 


\subsubsection{Thermogravimetric analysis}

Thermogravimetric analysis (TGA) was used to obtain information on the thermal decomposition behaviour of the PTPS residue the thermal degradation profile was used to obtain the proximate composition of the PTPS residue. TGA pyrolysis (under nitrogen) was set to operate from $20-500^{\circ} \mathrm{C}$, while combustion (in air) took place from $500-600{ }^{\circ} \mathrm{C}$. The thermogravimetric (TG) and the derivative thermogravimetric (DTG) plots of the PTPS residue adsorbent are shown in Figures 6(a) and (b) respectively. Cellulose and hemicellulose are the major components of the volatile matter, while the lignin is a main component in the formation of chars (Sanchez-Silva et al., 2012). These components have different initial decomposition temperatures due to their composition and this can be used to indicate the temperatures and regions of their elimination from the sample under investigation. Previous studies carried out by Stefany et al., (2005) observed that the sequence of degradation in lignocellulosic materials commences with the decomposition of hemicellulose between the temperature ranges $\left(150-350^{\circ} \mathrm{C}\right)$. The cellulosic material is the second component that degrades between the range $275-380^{\circ} \mathrm{C}$ and lignin degrades between $300-500^{\circ} \mathrm{C}$. The third stage of weight loss is the oxidation of the fixed carbon occurring from $500^{\circ} \mathrm{C}$ to $600^{\circ} \mathrm{C}$ with the resulting ash residue and this can be used to characterise the degradation profile of the PTPS residue. Examination of Figures 6(a) and (b) shows that there were 4 regions (each with an exothermic peak) with differential quantities of components eliminated by the thermal degradation process and these can be related to the different components on the PTPS residue. 


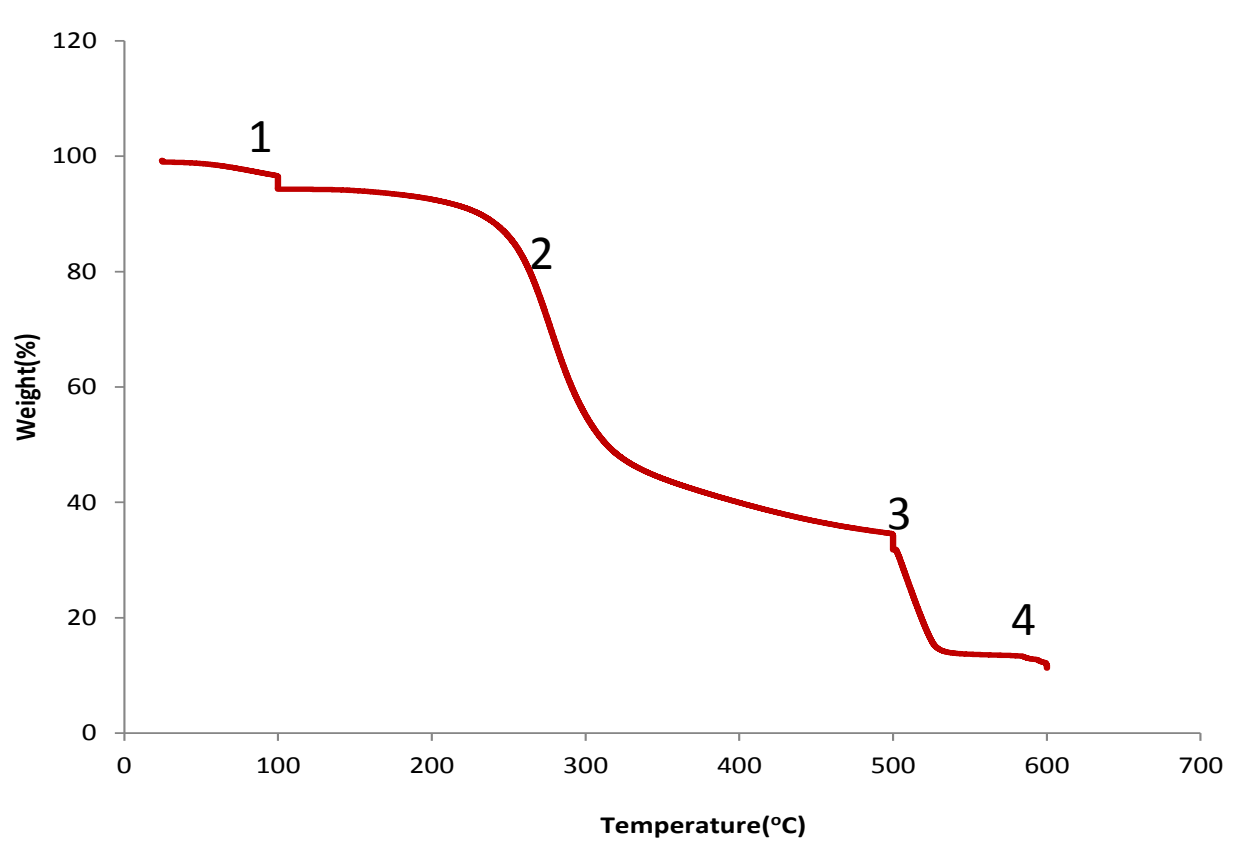

TGA for PTPS

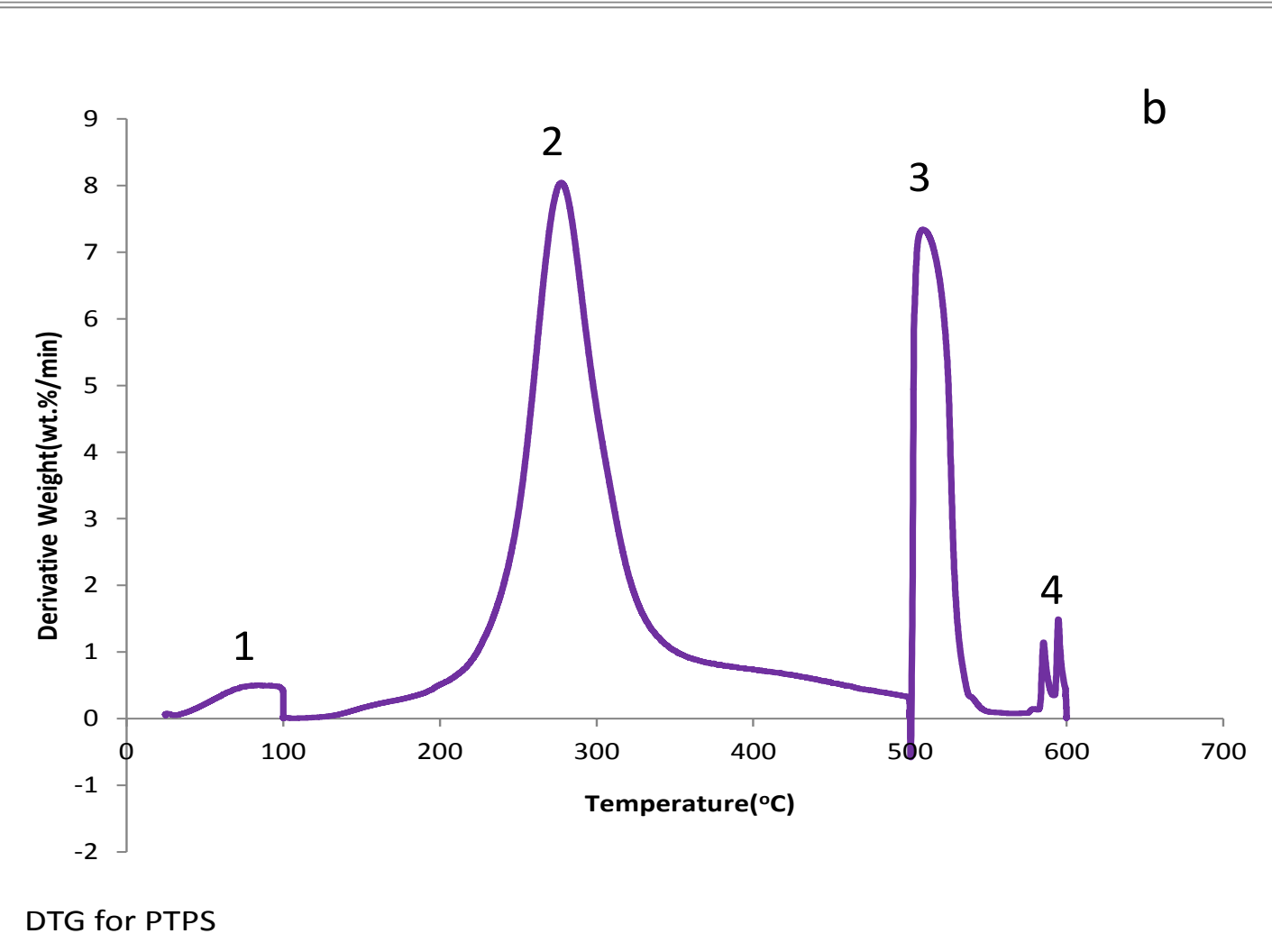

Figure 6: Thermogravimetric (a) and derivative thermogravimetric (b) plots of PTPS in $\mathrm{N}_{2}$ $\left(20-500^{\circ} \mathrm{C}\right) \& \operatorname{air}\left(500-600^{\circ} \mathrm{C}\right)$ 
The weight loss in the first stage (1) (moisture evolution) was $4.9 \%$ and this was as a result of

keeping the residue at this stage $\left(20-100^{\circ} \mathrm{C}\right)$ for 60 minutes to eliminate all moisture, the second stage (2) of the weight loss regime (evolution volatile component) was $62.4 \%$ with a maxima in the DTG plot (Fig. 6b) that can be associated with hemicellulose and cellulose decomposition between 180 and $380^{\circ} \mathrm{C}$. The third stage (3) is that of the oxidation of fixed carbon on the residue $(20.5 \%)$ and occurs between 500 and $600^{\circ} \mathrm{C}$ with final stage (4) being the ash component as the final residue which is composed of the inorganic elements $(11.2 \%)$. The degradation profile of the different components in the PTPS residue adsorbent is similar to profiles that have been reported in literature as noted by Titiloye et al., (2013) on the evaluation of the thermo-chemical characteristic of some agricultural waste from West Africa. Comparing the results in their study to the PTPS adsorbent, it is observed that the percentage moisture content of the PTPS adsorbent $(4.9 \%)$ was lower than that reported for the various agricultural wastes such as corn straw (9.15), corn cob (8.72), rice straw (7.23), rice husk (8.59), cocoa pod (10.29), Jatropha cakes (10.03), moringa cakes (10.38) and sugar cane bagasse (8.52). However, the moisture content of the PTPS residue was higher than that of Parinari fruit shell (2.65) also reported in the study. Also the percentage volatile matter component of the PTPS (62.4\%) was lower than those of the corn straw (75.02), corn cob (80.72), cocoa pod (68.47), Jatropha cakes (72.53), moringa cakes (75.08) Parinari fruit shell (78.17) and sugar cane bagasse (79.45). However, the volatile content of the PTPS residue was higher those of rice straw (45.68), rice husk (58.22) (Titiloye et al., 2013). The percentage fixed carbon of the PTPS residue (20.5) was higher than those of all the agricultural residues - corn straw (9.70), corn cob (7.60), cocoa pod (10.43), rice straw (1.33), rice husk (8.48), Jatropha cakes (10.97), and moringa cakes (8.26), Parinari fruit shell (14.51) and sugar cane bagasse (8.12) reported by Titiloye et al., (2013). Finally it was also observed that the percentage ash content of the PTPS residue (11.2) was higher than those of corn straw (6.13), corn cob (2.93), cocoa pod (10.81), Jatropha cakes (6.47), moringa cakes (6.28), Parinari fruit shell (4.67) and sugar cane bagasse (3.91) with exception of those of rice straw and rice husk which were 45.76 and 24.71 respectively.

\subsubsection{Fourier transform infrared (FTIR) spectroscopy}

The FTIR spectrum of the PTPS residue adsorbent was used to determine the functional groups present based on their characteristic vibrations. It is also used to confirm sorption mechanism as the vibrations associated with the functional groups present in lignocellulosic adsorbents will have shifts if they are involved in interactions with metal ions either as 
covalent, complexation, hydrogen bonding or other electrostatic interactions. The infrared spectrum of the PTPS adsorbent is shown in Figure 7, while that after $\mathrm{Cd}(\mathrm{II})$ ion sorption is presented in Figure 8.

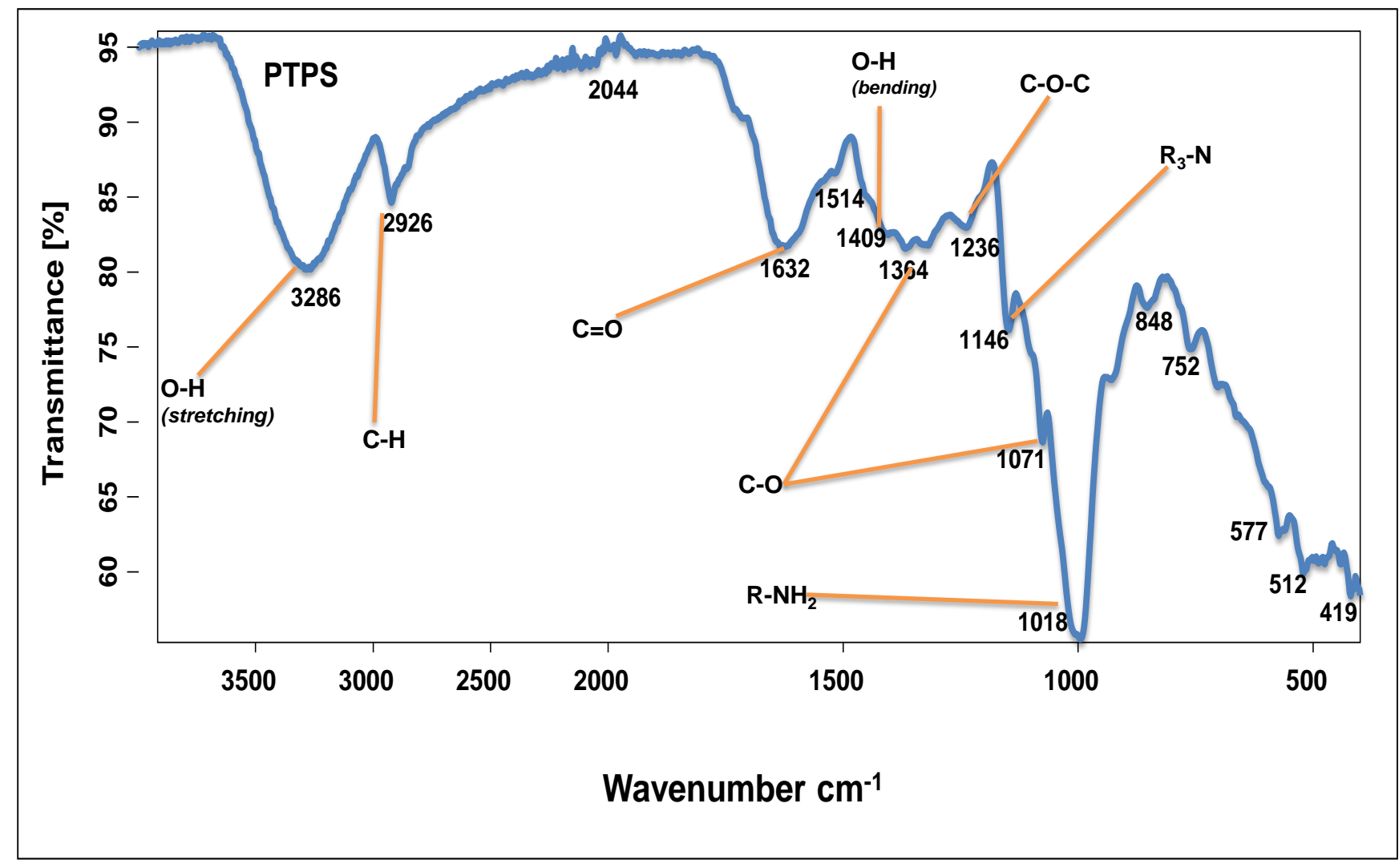

Figure 7: ATR-FTIR spectrum of Sweet potato adsorbent PTPS

The FT-IR spectrum in Fig. 7 indicates a strong broad peak at $3286 \mathrm{~cm}^{-1}$ which confirms the presence of free and $\mathrm{H}$-bonded $-\mathrm{OH}$ stretching vibration of the hydroxyl group within the cellulose, hemicellulose and lignin in the adsorbent structure (Ahmed et al., 2014). This can also be associated with the presence of water molecules adsorbed onto the adsorbent surface (Rao et al., 2006). The vibration observed at $2926 \mathrm{~cm}^{-1}$ corresponds to the $\mathrm{C}-\mathrm{H}$ stretching of the methyl and methylene groups in the polymers in the adsorbent such as lignin, cellulose and hemicellulose (Farooq et al., 2011). The carbonyl-C=O stretching vibration of aldehydes and ketones and the $\mathrm{C}=\mathrm{C}$ of the benzene ring stretching is indicated at $1632 \mathrm{~cm}^{-1}$ which is indicative of the aromatic compounds in the lignin components of the PTPS adsorbent (Farooq et al., 2011; Yang et al., 2007; Johari et al., 2015). The peaks at 1071 and $1364 \mathrm{~cm}^{-1}$ were assigned to the stretching vibrations of the hydroxyl and C-O stretching vibrations of the carboxylate group in the lignin, hemicellulose and cellulose (Naiya et al., 2011; Bodirlau et al., 2009; Fan et al., 2012). The O-H bending vibration peak is observed at $1409 \mathrm{~cm}^{-1}$ and the 
peak at $1236 \mathrm{~cm}^{-1}$ can be associated to the $\mathrm{C}-\mathrm{O}-\mathrm{C}$ stretching vibration of the aryl-alkyl-ether linkages and phenolic $\mathrm{O}-\mathrm{H}$ plane deformation in the cellulose and hemicellulose components of the lignocellulosic structure of the adsorbent (Yang et al., 2007; Bodirlau et al., 2009; Fan et al., 2012). Furthermore, the primary amine functional groups can be associated to the vibrations observed at $1018 \mathrm{~cm}^{-1}$, while the vibration at $1146 \mathrm{~cm}^{-1}$ may be associated to the tertiary amine stretching on the adsorbent surface (Ahmed et al., 2014). The carboxylate and hydroxyl groups on lignocellulosic materials have been reported to have the potential to interact with metal ions during adsorption (Naiya et al., 2011) and since the PTPS adsorbent had these groups, their role in adsorption of metal ions was examined by characterising the PTPS-Cd adsorbent using FT-IR after Cd (II) adsorption and this is presented in Figure 8.

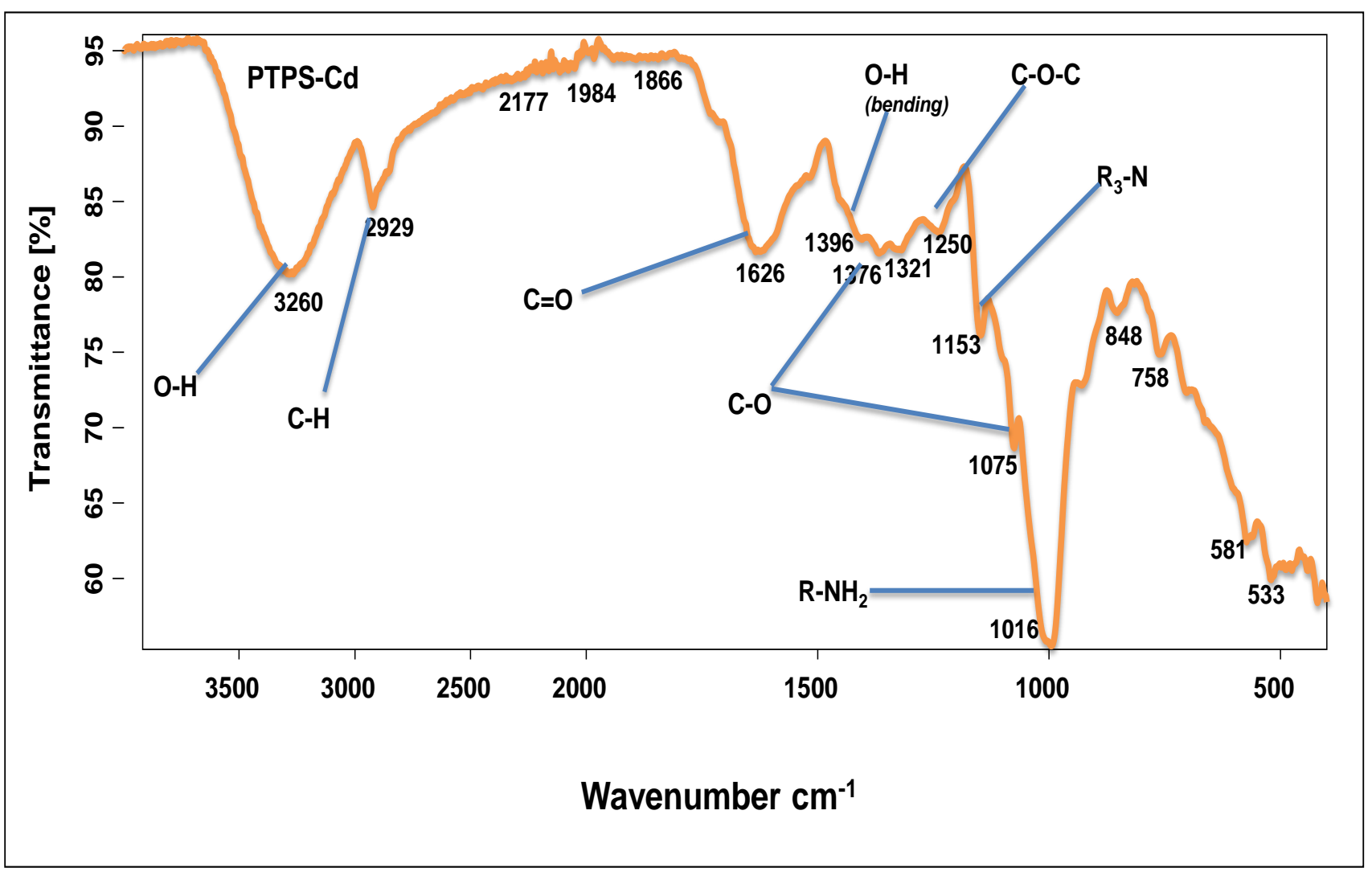

Figure 8: ATR-FTIR spectrum of PTPS adsorbent after Cd(II) adsorption

From Figure 8 it can be observed that spectrum of loaded adsorbent has some characteristic frequency shifts in vibration intensity on some of the bands. One prominent band is the $\mathrm{OH}$ stretching and bending vibrations which confirms the participation of these groups on the residue surface in adsorption interactions. The $\mathrm{O}-\mathrm{H}$ group vibration present at $3286 \mathrm{~cm}^{-1}$ in Figure 7 was observed to shift to $3260 \mathrm{~cm}^{-1}$ after the adsorption of $\mathrm{Cd}(\mathrm{II})$ ions -PTPS-Cd (Figure 8) due to interactions with the metal ions. The band representing the carboxylate functional group stretching vibrations was also observed to shift from $1364 \mathrm{~cm}^{-1}$ to $1376 \mathrm{~cm}^{-1}$ 
in the adsorbent after Cd (II) ion sorption. These shifts in vibrations presupposes that the hydroxyl and carboxylate groups on the PTPS adsorbent had chemical interactions with the $\mathrm{Cd}(\mathrm{II})$ ion which may be due to surface adsorption and complexation resulting in the decrease in the frequency of the vibrations (Naiya et al., 2011). Furthermore, from Figure 8 it can be observed that there were shifts in vibrations associated with the O-H bending vibrations (1409 to $\left.1396 \mathrm{~cm}^{-1}\right)$, C-O-C stretching of the alkyl ether groups $\left(1236\right.$ to $\left.1250 \mathrm{~cm}^{-1}\right)$ and the disappearance of the carboxyl $(\mathrm{C}=\mathrm{O})$ vibration observed at $1514 \mathrm{~cm}^{-1}$. These shifts in the vibrations associated with these functional groups indicated that inference can also be made that the $\mathrm{Cd}(\mathrm{II})$ bonding on the PTPS adsorbent were to functional groups such as carboxylate groups in (cellulose, hemicellulose and lignin), phenolic groups in (lignin and extractives) and hydroxyl groups associated with cellulose, lignin, hemicellulose, extractives and pectin (Pandey et al., 2015). The shift in the vibrations of the functional groups after metal ion sorption as observed in FTIR spectrum of the PTPS adsorbent after Cd(II) adsorption can be explained based on the change in coordination sites of the functional groups due to the interactions with the $\mathrm{Cd}(\mathrm{II})$ ion. This observation has also been reported by Thirumavalavan et al.,(2011) in their study on the Fourier Transform spectroscopic analysis of fruit peels before and after adsorption of heavy metal ions from aqueous solution. In their study, it was observed that the $\mathrm{C}-\mathrm{H}$ peak intensity was reduced on the fruit peels after adsorption, while on some peels the peaks were absent.

\subsection{Metal ion sorption studies}

From the characterisation of the residue adsorbents a number of parameters were chosen to evaluate their impact on the removal of Cd(II) using the PTPS residue adsorbent. From the results of the zeta potential and pHpzc characterization of the residue, the $\mathrm{pH}$ of 6.5 was chosen for $\mathrm{Cd}$ (II) ion sorption studies as the results from the pHpzc characterisation previously described indicated that the pHpzc of the PTPS adsorbent was 6.3. Thus for an adsorption system designed for the removal of positive species $\{\mathrm{Cd}(\mathrm{II})\}$ to be effective, the $\mathrm{pH}$ of the adsorbate must be higher than the pHpzc (Noamanbhay and Palanisamy, 2005), hence the $\mathrm{pH}$ of 6.5 was chosen. This $\mathrm{pH}$ is also within the window of $\mathrm{pH}$ for discharged effluents (6.5-9.5) based on the WHO standard guidelines (Ipeaiyeda and Onianwa, 2011). The parameters studied were contact time, $\mathrm{pH}$ and in addition equilibrium sorption studies was also carried out to evaluate the metal ion loading for the adsorbent. For the determination of 
metal ion loading after sorption the amount of metal ion adsorbed was computed based on eqn.1.

\subsubsection{Effect of Adsorbate $\mathrm{pH}$}

The $\mathrm{pH}$ of an aqueous solution is a fundamental parameter that influences the sorption of metal ions due to its effect on the speciation of ions in solution and hence the types of ions that are available at particular hydrogen or hydroxyl ion concentrations to facilitate their removal by the adsorbents (Teker et al., 1999; Antunes et al., 2003). The effect of pH was studied based on the procedure described previously in this study. $\mathrm{pH} 2-10$ was taken as the window for analysis for all adsorbents as the $\mathrm{pH}$ of range for discharged effluents based on WHO standard guidelines $(6.5-9.5)$ is within this window (Ipeaiyeda and Onianwa, 2011). In addition, metal ion precipitation has been reported for both $\mathrm{Cd}(\mathrm{II})$ ions as the $\mathrm{pH}$ increases from 10 to 12 and this was also observed to occur during the evaluation of these heavy metal ions using natural adsorbents (Ho et al 2002). The effect of $\mathrm{pH}$ on $\mathrm{Cd}(\mathrm{II})$ ion sorption is shown in Figure 9 and from the figure, it is observed that the optimum $\mathrm{pH}$ for $\mathrm{Cd}$ (II) ion removal using the PTPS adsorbent was 7. The initial and final $\mathrm{pH}$ of the adsorbate solution during the sorption of $\mathrm{Cd}(\mathrm{II})$ ions is also presented in Table 3. From Figure 9, it can be observed that the amount of $\mathrm{Cd}(\mathrm{II})$ ions adsorbed increased slowly at first with increase in initial $\mathrm{pH}$ from 2 to 4 , reached a maximum value at $\mathrm{pH} 7.0$ for $\mathrm{Cd}(\mathrm{II})$ and thereafter gradually decreased as the $\mathrm{pH}$ increased up to $\mathrm{pH} 10$. At $\mathrm{pH} 2$, the amount of $\mathrm{Cd}(\mathrm{II})$ adsorbed ions was least when compared to the other $\mathrm{pH}$ values and it is presumed that the amount adsorbed at $\mathrm{pH} 2$ was low due to the influence of protons in solution leading to a charge reversal on the adsorbent surfaces which favours the repulsion of the metal on ions ultimately leading to a reduction in the binding ability of the adsorbent. 
Table 3: Initial and final $\mathrm{pH}$ of adsorbate solution for PTPS sorption of Cd(II)

\begin{tabular}{lrrrrrrrrr}
\hline Initial & 2 & 3 & 4 & 5 & 6 & 7 & 8 & 9 & 10 \\
& & & & & & & & & \\
Final & 2.4 & 3.3 & 5.2 & 5.2 & 5.3 & 5.4 & 7 & 7.8 & 9.8 \\
\hline
\end{tabular}

This can be explained based on the surface complexation theory which states that the increase in metal removal as $\mathrm{pH}$ increases can be associated to a decrease in competition between protons and metal species for the surface of active sites and by a decrease in positive charge (Krishnani et al., 2008). Hence low pH values would favour protonation of the groups at the binding sites (hydroxyl, carboxyl, phenolic) and high $\mathrm{pH}$ values on the other hand would lead to the precipitation of metals especially at alkaline medium ( $\mathrm{pH} 9$ to 10) thereby reducing the amount of metal ions adsorbed by the PTPS adsorbents as can be observed in Figure 9. It was also observed from Table 3, that the final $\mathrm{pH}$ after metal ion sorption was lower that the initial $\mathrm{pH}$ between $\mathrm{pH}$ 6-8 where maximum sorption of the $\mathrm{Cd}(\mathrm{II})$ existed as observed in Figure 9. This can be related the mechanism of $\mathrm{Cd}(\mathrm{II})$ uptake onto the adsorbent which may 
cause the displacement of hydrogen ions $\left(\mathrm{H}^{+}\right)$. Furthermore, the sorption of $\mathrm{Cd}(\mathrm{II})$ by the

The effect of contact time on the removal of $\mathrm{Cd}(\mathrm{II})$ metal ion from an aqueous solution using the PTPS adsorbent is an important characteristic of an adsorption system as it gives insight into the nature of adsorbent - adsorbate interactions as well as the transport profiles during metal ion uptake. The effect of contact time on Cd(II) ion uptake using the PTPS adsorbent was studied at $\mathrm{pH} 6.5$ with initial metal ion concentration of $500 \mathrm{mgl}^{-1}$ temperature of $25^{\circ} \mathrm{C}$ and a volume of $0.1 \mathrm{~L}$. The amount of the PTPS adsorbent used was $2.0 \mathrm{~g}$ and the duration of kinetic studies was from 5 to 1440 minutes $(72 \mathrm{~h}$ ). The kinetic profile for $\mathrm{Cd}(\mathrm{II})$ is shown in Figure 10 . 
Figure 10: Effect of contact time on Cd(II) ion sorption on PTPS adsorbent Initial conc$500 \mathrm{mgL}^{-1}$, pH-6.5 and $2.0 \mathrm{~g}$ of adsorbent.

From Figure 10, it is observed that there was a rapid uptake of metal ions by the adsorbents up to 180 minutes and a gradual loading up to 1440 minutes. The $\mathrm{Cd}(\mathrm{II})$, ion maximum loading at attainment of equilibrium time for the PTPS adsorbent was $11.34 \mathrm{mgg}^{-1}$. An examination of Figure 10 indicates that the metal ion loading on the adsorbent occurred in two stages over the duration of contact. The first stage was characterised by a fast uptake lasting up to 180 minutes for all the residues and the second stage proceeded slowly from 180 minutes up till 1440 minutes where equilibrium was attained. This two stage process can be explained based on the availability of active sites on the PTPS adsorbent for Cd(II) ion loading. At inception of the metal ion-adsorbent contact, there are a number of readily accessible active sites on the adsorbent surface making the uptake of the $\mathrm{Cd}(\mathrm{II})$ ions onto these sites rapid. The shape of the curve is due to a combination of two processes, a rapid process and a slow process. The rapid process could be due to primary attachment to "exposed" sites, while the slow process could due to the re-arrangement of attached Cd (II) to hidden active sites. Alternatively the rapid process could be viewed as a result of the attachment to "exposed" sites with a slow pore diffusion process occurring in parallel as $\mathrm{Cd}(\mathrm{II})$ diffuses along the pores to "enclosed" active sites leading to the slow process. (Sarada et al.,2014). Krishnani et al., (2008) also reports a two stage metal ion sorption for rice husk for the removal of a number of heavy metal ions in which the first stage was within $90-120$ minutes after which equilibrium was reached at 150 minutes contact time. It is pertinent to note that the maximum loading for the $\mathrm{Cd}(\mathrm{II})$ ion for the adsorbent after 1440 minutes $(72 \mathrm{~h})$ 
$\left(11.3 \mathrm{mgg}^{-1}\right)$ was close to the values after 180 minutes $\left(10.6 \mathrm{mgg}^{-1}\right)$. Hence from the metal ion

kinetic results, the time 180 minutes was taken as the time for further sorption experiments. This was because in the design of sorption systems, the attainment of rapid kinetics for metal ion sorption is an important parameter as it facilitates the utilization of smaller reactor volumes thereby ensuring high sorption efficiency and improves the economics of the adsorption process, which is a fundamental parameter in the scale-up of batch adsorption systems (Loukidou et al., 2004; Perez-Marin et al., 2007).

\subsubsection{Kinetic Modelling}

The kinetics of metal ion sorption processes in a batch system is also used to determine the type of processes that govern the mechanism of sorption. Kinetic data for metal ion sorption can be used to determine the type of mechanism governing the process and possibly also the potential rate controlling step of the adsorption process. The mechanism of an adsorption process depends on the physical and chemical characteristics of the adsorbent as well as the mass transfer process from the adsorbate onto the adsorbent (Kumar et al., 2014). Hence the discrimination of an adsorption mechanism may often involve the use of kinetic models that ascertain the mechanism governing the metal ion sorption based on shapes and fitting of kinetic plots which have fundamental assumptions in their design that can be extrapolated to the system under investigation. The information from the kinetic modelling can be used to interpret the type of transport mechanism and the description of the sorption process can therefore be carried out (Farooq et al., 2011; Kakalanga et al, 2012; Perez-Marin et al., 2007). In this study, two adsorption reaction kinetic models \{pseudo-first order (PFO) and pseudosecond order (PSO) $\}$ and one adsorption diffusion model (intraparticle diffusion model) were applied to investigate the kinetics of Cd(II) ion adsorption onto the PTPS adsorbent.

\section{Pseudo first order model}

In 1898, Lagergren presented the first order rate equation for the adsorption of ocalic acid and malonic acid onto charcoal to explain the kinetics of adsorption on solid surfaces. In order to distinguish the kinetic processes based on concentration of solution and adsorption capacity of solid, this Lagergren equation is called the pseudo-first order equation (Lagergren, 1898; Ho, 2004a) was the first rate equation developed for sorption in liquid/solid systems and it is based on solid capacity (Ho, et al., 2004). It is one of the most widely used rate equations reported in adsorption kinetic literature. Assuming that in a solid liquid adsorption system, the 
adsorption rate was proportional to the number of effective adsorption sites and then the rate of adsorption would be expressed as eqn (2):

$$
\frac{d q_{t}}{d_{t}}=K_{1}\left(q_{e}-q_{t}\right)
$$

where $\mathrm{q}_{\mathrm{e}}$ and $\mathrm{q}_{\mathrm{t}}$ are the sorption capacities, at equilibrium and at time $\mathrm{t}$, respectively (mg.g $\mathrm{g}^{-1}$ ), while $K_{1}$ is the rate constant of the pseudo-first order sorption $\left(\mathrm{min}^{-1}\right)$. After integration and applying boundary conditions $\mathrm{t}=0$ to $\mathrm{t}=\mathrm{t}$ and $\mathrm{q}_{\mathrm{t}}=0$ to $\mathrm{q}_{\mathrm{t}}=\mathrm{q}_{\mathrm{t}}$, the integrated form of eqn (3) is expressed as:

$$
\log \left(q_{e}-q_{t}\right)=\log \left(q_{e}\right)-\frac{k_{1}}{2.303} t
$$

Equation 3 is the linear form of the equation and the most common form of the pseudo first order (PFO) equation reported in literature for the description of sorption. Xuan et al., (2006) used the linear pseudo first order equation to describe the kinetics of $\mathrm{Pb}$ (II) biosorption onto pre-treated chemically modified orange peel. Ho et al., (2004) has also reported on the sorption of $\mathrm{Pb}$ (II) from aqueous solutions using tree fern adsorbent in which the linear form of the PFO equation was used. However, a number of studies have reported that the linear form of the PFO equation may lead to error propagation in the results due to the transformation of the PFO equation which is in a non-linear form to a linear form thereby implicitly altering the error structure in the determination of the model parameters (Ho, 2004b; Lin and Wang, 2009). The non-linear form of the PFO is given as eqn (4) as:

$$
q_{t}=q_{e}\left(1-e^{-k_{1} t}\right)
$$

The non-linear form of the PFO will be used to model the kinetics of sorption of $\mathrm{Pb}(\mathrm{II})$ and $\mathrm{Cd}(\mathrm{II})$ onto the different adsorbents developed in this study and eqn. 4 represents the reversible interaction between the adsorbate and adsorbent and is used for the prediction of the physisorption of the adsorbates onto the adsorbents in the system under consideration.

\section{Pseudo second order model}

The reaction kinetics of adsorption is the basis of the adsorption reaction models used in kinetic modelling and one of the most commonly used reaction models for the description of the kinetics of adsorption is the pseudo-second order model proposed by Y.S. Ho in Ho, (2006). This model was proposed in an attempt to present the equation that represents the 
adsorption of divalent metals onto sphagnum moss peat during agitation. An assumption was made that the process may be second-order and that sorption depends on the adsorption capacity of the adsorbent which is associated with the number of available active sites. This pseudo second order kinetics is presumed to proceed via chemisorption which involves valence forces through the sharing or exchange of electrons between the peat and the divalent metal ion as covalent forces (Ho, 2006). In the work of Ho (2006), the adsorbent used was peat which has a number of polar functional groups and these include ketones, phenolic acids and aldehydes. These chemical species on the surface of the peat are active sites that can be interact via chemical bonding. These groups are therefore the sites for the cation exchange capacity of the peat. Based on the above process and according to Coleman et al, (1956), the peat-copper reaction may be represented in two different forms as shown in the equations below:

$$
\begin{aligned}
& 2 P^{-}+\mathrm{Cu}^{2+} \leftrightarrow \mathrm{CuP}_{2} \\
& 2 \mathrm{HP}+\mathrm{Cu}^{2+} \leftrightarrow \mathrm{CuP} P_{2}+2 \mathrm{H}^{+}
\end{aligned}
$$

where $\mathrm{P}^{-}$and $\mathrm{HP}$ are polar sites on the peat surface.

Here the rate of the second order reaction may be dependent on the amount of the divalent metal ions on the surface of the peat at time " $\mathrm{t}$ " and the amount of the divalent metal ions adsorbed at equilibrium, the assumption is also may that the adsorption follows the Langmuir equation (Ho and McKay, 2000; Ho, 2006; Qiu et al., 2009). Hence, the rate expressions for the adsorption according to Ho and McKay, (2000) can be described by eqns. (7) and (8) as:

$$
\frac{d(P)_{t}}{d t}=K\left[(P)_{0}-(P) t\right]^{2}
$$

or

$$
\frac{d(H P)_{t}}{d t}=K\left[(H P)_{0}-(H P) t\right]^{2}
$$

Where $(\mathrm{P})_{\mathrm{t}}$ and $(\mathrm{HP})_{\mathrm{t}}$ are the number of active sites occupied on the peat at time $\mathrm{t}$, and $(\mathrm{P})_{0}$ and $(\mathrm{HP})_{0}$ are the number of equilibrium sites available on the peat. Therefore the driving force $\left(\mathrm{q}_{\mathrm{e}}-\mathrm{q}_{\mathrm{t}}\right)$ is proportional to the available fraction of active sites. Thus from the above, the kinetic rate equation can be written as follows (Ho and McKay, 2000; Ho and Chiang, 2001; Ho, 2006): 


$$
\frac{d q t}{d t}=K_{2}(q e-q t)^{2}
$$

Where $\mathrm{q}_{\mathrm{e}}$ and $\mathrm{q}_{\mathrm{t}}$ are the sorption capacities at equilibrium and at time $\mathrm{t}$, respectively ( $\mathrm{mg} \mathrm{g}^{-1}$ ) and $\mathrm{K}_{2}$ constant is the rate constant of the pseudo-second order sorption $\left(\mathrm{g} \mathrm{mg}^{-1} \mathrm{~min}^{-1}\right)$. For the boundary conditions $t=0$ to $t=t$ and $q_{t}=0$ to $q_{t}=q_{t}$, the integrated form of eqn. (9) becomes (Ho and McKay, 2000):

$$
\frac{1}{q e-q t}=\frac{1}{q e}+K_{2} \cdot t
$$

This is the integrated rate law for a pseudo-second order reaction. Eqn. (10) can be rearranged to obtain:

$$
q_{t} \quad=\frac{t}{\frac{1}{k_{2} q_{e}^{2}}+\frac{t}{q_{e}}}
$$

Eqn (11) has the linear form:

$$
\frac{t}{q t}=\frac{1}{K_{2} q e^{2}}+\frac{1}{q e} t
$$

Where $h\left(\mathrm{mg} \cdot \mathrm{g}^{-1} \cdot \mathrm{min}^{-1}\right)$ can be regarded as initial sorption rate as $q_{t} t t \rightarrow 0$, hence:

$$
h=K_{2} \cdot q e^{2}
$$

Equation (13) can be written as:

$$
\frac{t}{q t}=\frac{1}{h}+\frac{1}{q e} t
$$

Equation (14) is the linear form of the pseudo second order equation (PSO) that is commonly reported in literature. This linear form causes distortion in the error structure when used to plot the PSO model leads to differences in model data between the non-linear and linear techniques in modelling the pseudo second order equation (Ho, 2004b; El-Khaiary et al., 2010). Hence, the better option is the use of the non-linear method as the pseudo second order equation is a non-linear equation and the numerical optimization used to determine parameters will provide a more accurate representation of the model and the parameters 
within it than a linearization plot which often leads to propagation of errors in a model, (ElKhaiary et al., 2010). This non-linear approach will be applied for the modelling of the sorption kinetics of $\mathrm{Cd}(\mathrm{II})$ ion sorption onto the PTPS adsorbent and the non-linear PSO equation that will be used for the kinetic modelling is given by Lin and Wang, (2009) as:

$$
q_{t}=\frac{K_{2} \cdot q e^{2} t}{1+K_{2} q e t}
$$

Thus, equation (15) was used to model the non-linear pseudo second order kinetics for the sorption reported in this work and it assumes a stronger interaction between the adsorbate and adsorbent based on the chemisorption of the adsorbates onto the adsorbents in the system under consideration. One advantage of using the pseudo second order equation for the modelling of adsorption kinetics is that there is no need to know the equilibrium capacity from the experiments, as this value, the pseudo second order rate constant and the initial adsorption rate can be calculated from the model (Ho, 2006).

The co-efficient of determination $\left(\mathrm{r}^{2}\right)$ and two non-linear error parameters the chi-square test $\left(\chi^{2}\right)$ and the root mean square error (RMSE) were used to analyse the two kinetic models (Basha et al., 2009; Hossain et al., 2013). The coefficient of determination $\left(\mathrm{r}^{2}\right)$ formula is given in Eqn. 16 as follows:

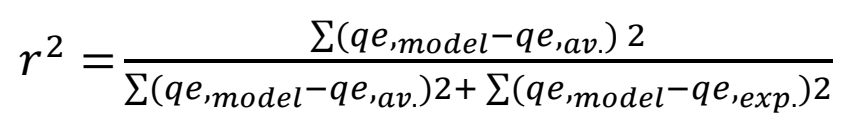

The non-linear error functions of Chi-square test $\left(\chi^{2}\right)$ and the root mean square error (RMSE) were used to evaluate the model and these are given in eqns. 17 and 18 as follows:

$$
\begin{gathered}
\chi 2=\sum_{n=1}^{n}\left(\frac{\left(q e_{\text {exp. } .}-q e_{,_{\text {model.n. }}}\right)^{2}}{\left(q e_{\text {exp. }}\right)}\right. \\
R M S E=\sqrt{\frac{1}{m-p}} \sum_{i=1}^{m}(q m-q e)^{2}
\end{gathered}
$$

Where: $q e$, model is the equilibrium capacity obtained from the isotherm model $q e$, exp. is the equilibrium capacity obtained from experiment $q e, a v$ is the average $q_{e, \text { exp. }}$ $q e$ and $q m$ are the measured and model amount of cadmium(II) ion adsorbed at time $\mathrm{t}$ respectively 
$m$ is the number of data points evaluated

$p$ is the number of parameters in the regression model

Whereby smaller the RMSE and $\chi^{2}$ values and the higher the $r^{2}$ value indicates better fitting of model with the experimental data (Basha et al., 2009).

Kinetic modelling of Cd(II) sorption using the PFO and PSO equations were carried out using the solver add-in optimization procedure in Microsoft excel 2010. The plots of the PFO are PSO models are presented in Figures 11. From these models, the kinetic parameters and their respective error functions obtained are presented in Table 4.

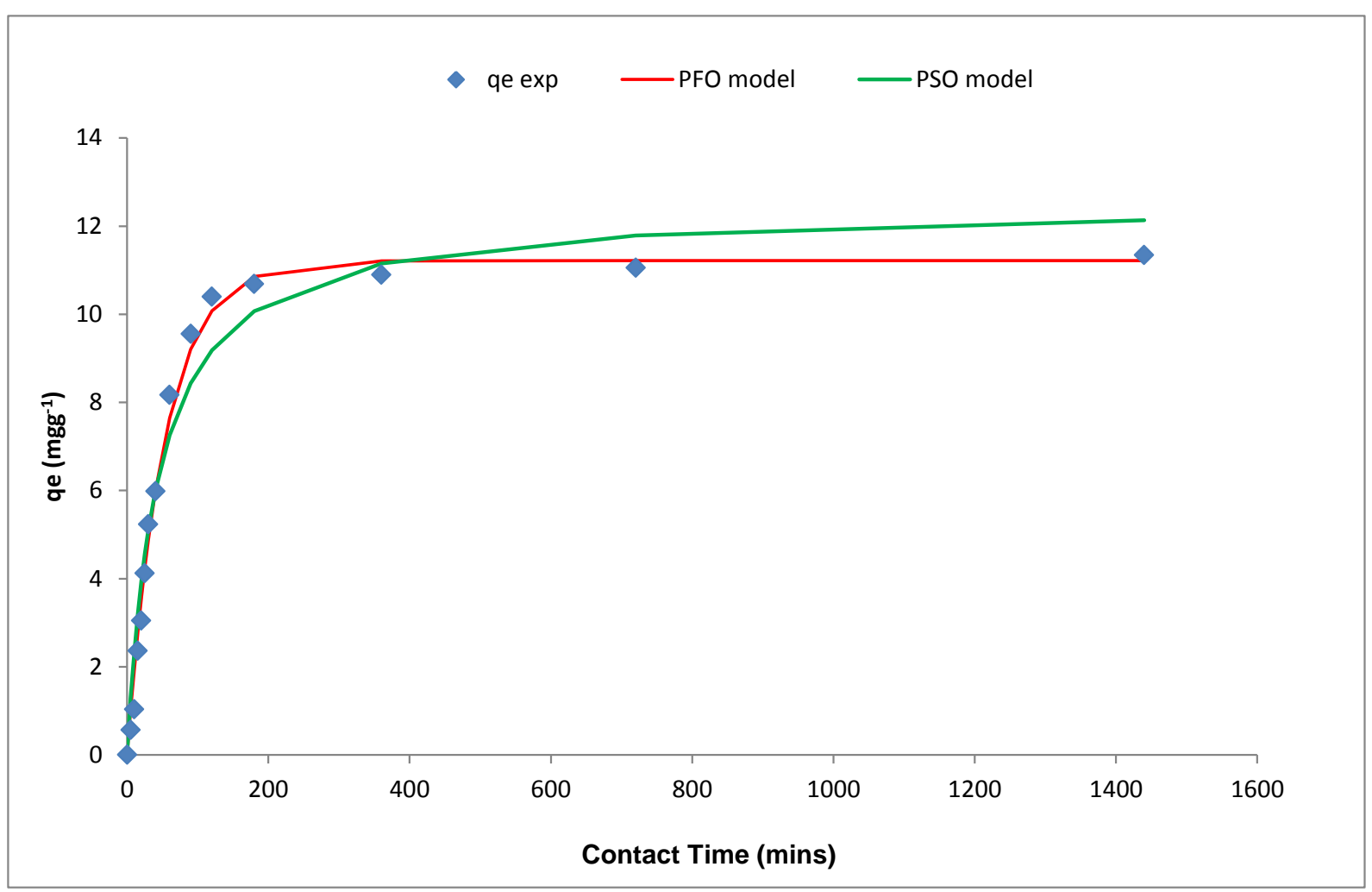

Figure 11: Pseudo-first order (PFO) \& pseudo-second order (PSO) kinetic plot for PTPS adsorbent

The results presented in figure 11 and Table 4 indicates that the two models (PFO\& PSO) could be used to characterise the kinetics of $\mathrm{Cd}(\mathrm{II})$ ion sorption and their prediction of the parameter ( $\mathrm{qe}$, model) is close to the result obtained from the experimental analysis of $\mathrm{Cd}(\mathrm{II})$ ion sorption. For the PFO model the qe, model obtained was $11.2 \mathrm{mgg}^{-1}$ and the rate constant of the pseudo first order reaction was $1.91 \times 10^{-2} \mathrm{~min}^{-1}$, while for the PSO model the qe, model from the non-linear optimization was $12.5 \mathrm{mgg}^{-1}$ and the rate constant of the pseudo second order reaction was $1.85 \times 10^{-3} \mathrm{gmg}^{-1} \mathrm{~min}^{-1}$. 
These two models have different fundamental asssuptions that premise their existence and this is used to interprete the significace of the rate constants. For the PFO model, the rate constant $\mathrm{K}_{1}$ is based on the relationship between the sorption rate and equilibrium, whereby the assumption is that the kinetic rate is dependent on the concentration of ions in solution (Miyake et al., 2013; De Haro-Del Rio et al., 2015; Qiu et al., 2009). On the other hand for the PSO model, the rate constant $\mathrm{K}_{2}$ is based on the assumption that the chemisorption based interactions between the ions and the sorbent are the rate limiting step, whereby sorption is dependent on the adsorptive solid capacity in the form of available fraction of active sites on adsorbent (Ho and McKay, 1999; Ho and McKay, 2004; De Haro-Del Rio et al., 2015; Qiu et al., 2009; Ho and McKay, 1998).

Table 4: Kinetic models parameters for Cd(II) sorption on PTPS adsorbent

\begin{tabular}{cll}
\hline \multicolumn{1}{c}{ Kinetic Models } & Parameters & Values \\
\hline & $\mathrm{qe}_{\text {,cal }}\left(\mathrm{mgg}^{-1}\right)$ & 11.2 \\
& $\mathrm{~K}_{1}\left(\mathrm{~min}^{-1}\right)$ & $1.91 \mathrm{E}-02$ \\
Pseudo-first order & $\mathrm{r}^{2}$ & 0.99 \\
& $\chi 2$ & 0.02 \\
& $\mathrm{RMSE}$ & $8.84 \mathrm{E}-02$ \\
& $\mathrm{qe}_{\text {,cal }}\left(\mathrm{mgg}^{-1}\right)$ & 12.5 \\
& $\mathrm{~K}_{2}\left(\mathrm{gmg}^{-1} \min ^{-1}\right)$ & $1.85 \mathrm{E}-03$ \\
Pseudo-second order & $\mathrm{h}^{2}\left(\mathrm{mgg}^{-1} \mathrm{~min}^{-1}\right)$ & 0.29 \\
& $\mathrm{r}^{2}$ & 0.96 \\
& $\chi^{2}$ & 0.09 \\
& $\mathrm{RMSE}^{2}$ & $3.52 \mathrm{E}-01$ \\
& & 1.119 \\
Intraparticle Diffusion & $\mathrm{K}_{\mathrm{id}}\left(\mathrm{mgg}^{-1} \mathrm{~min}^{-0.5}\right)$ & $8.96 \mathrm{E}-01$ \\
& $\mathrm{C}$ & 0.98 \\
\hline
\end{tabular}

The assumption of the pseudo-second order model is that one cadmium ion is adsorbed onto two sorption sites on the surface of the PTPS adsorbent which can be represented as eqn(19) according to Boparai et al., (2011).

$2 \mathrm{~A}+\mathrm{Cd}^{2+}{ }_{\text {sol }} \rightarrow \stackrel{\mathrm{k} 2}{\rightarrow} \rightarrow \mathrm{A}_{2} \mathrm{Cd}_{\text {solid phase }}$

Where $\mathrm{A}$ is an unoccupied sorption site on the adsorbent and $\mathrm{K}_{2}$ is the pseudo second order rate constant $\left(\mathrm{gmg}^{-1} \mathrm{~h}^{-1}\right)$. From the plot in Figure 11 and Table 4, it is observed that the $\mathrm{q}_{\mathrm{e}, \text { model }}$ of the PSO is after $72 \mathrm{~h}$ sorption is $12.5 \mathrm{mgg}^{-1}$, while that of the PFO model is $11.2 \mathrm{mgg}^{-1}$, whereas and the qe, exp was $11.34 \mathrm{mgg}^{-1}$, therefore it can be deduced that the value of $\mathrm{q}_{\mathrm{e}}$ from 
the PFO model is in closer agreement to the value obatined experimentally. Thus, it can be the PSO order model and this can also be seen in the error parameters and correlation coefficient values. This suggest that the kinetics supports the assumption that the rate limiting step of $\mathrm{Cd}(\mathrm{II})$ ion sorption onto the PTPS adsorbent is dependent on the concentration of the Cd(II) ions in solution (Kumar et al., 2014). However, the closeness of the parameters obtained from the PSO indicate that chemical interactions between the ions in the adsorbate solution and the adsorbent may still influence sorption kinetics but this may depend on the rate of diffusion.This implies that pore diffusivity of the ions onto the active sites may also influence the kinetics as previously discussed in the analysis of the two stage metal uptake (fast and slow) kinetics of $\mathrm{Cd}(\mathrm{II})$ ion sorption. To evaluate the duffusion effect on the kinetics of $\mathrm{Cd}(\mathrm{II})$ ion sorption the intraparticle diffusion model was used to descriminate the kinetics of $\mathrm{Cd}(\mathrm{II})$ ion sorption.

\section{Intraparticle Diffusion Model}

Diffusion mass transport models have been applied to sorption systems and their role in pollutant sorption is extremely important. Generally, the adsorption process description using these diffusion models are usually based on one or more of the following, mechanistic steps:

(i) Diffusion of the solute from the solution to the film surrounding the particle.

(ii) Diffusion from the film to the particle surface (external diffusion),

(iii) Diffusion from the film to the internal sites (surface or pore diffusion)

(iv) Metal ion uptake which can involve several mechanisms

The Weber and Morris intraparticle diffusion model is based on the assumption that the adsorption process may be controlled either by one of the following steps such as; film diffusion, pore diffusion, surface diffusion and adsorption onto the adsorbent pore surface or a combination of more than one step (Weber and Morris, 1963; Fierro et al., 2008). These regimes can be obtained in a stirred batch system, wherein the diffusive mass transfer can be related by an apparent diffusion co-efficient, which fits into an experimental sorption rate data (Fierro et al., 2008). The intraparticle diffusion model assumes that in batch adsorption process, the adsorbate diffuse into the interior of the adsorbent and this process is dependent on the square root of time $\left(t^{1 / 2}\right)$ rather than time $(t)$, where the intercept $(C)$ is related to the boundary layer (Azarudeen et al., 2015; Qiu et al., 2009; Gurses et al., 2014; Alkan et al., 2007). The relationship for the model is given as follows: 


$$
q_{t}=K_{i d} t^{1 / 2}+\mathrm{C}
$$

Where $\mathrm{q}_{\mathrm{t}}$ is the amount of $\mathrm{Cd}$ (II) adsorbed at time $\mathrm{t}\left(\mathrm{mgg}^{-1}\right), \mathrm{K}_{\mathrm{id}}$ is the intraparticle diffusion constant $\left(\mathrm{mgg}^{-1} \mathrm{~min}^{-1 / 2}\right)$ and $\mathrm{C}$ is the constant related to the thickness of the boundary layer (Ahmadi et al., 2015). A plot of qt vs $\mathrm{t}^{1 / 2}$ gives a straight line if intraparticle diffusion is the rate limiting step in the adsorption. However, this is not always the case as other processes such as film diffusion and equilibrium adsorption may also be rate limiting for different stages of the kinetic profile and this will result in multi-linearity in the intraparticle diffusion plot (Fierro et al., 2008; Basha et al., 2009; Qiu et al., 2009). The plot of the Weber and Morris intraparticle diffusion model for the adsorption of $\mathrm{Cd}(\mathrm{II})$ ion onto the PTPS adsorbent is shown in Figures 12 and 13 and Table 4 presents the model constants obtained from the plot.

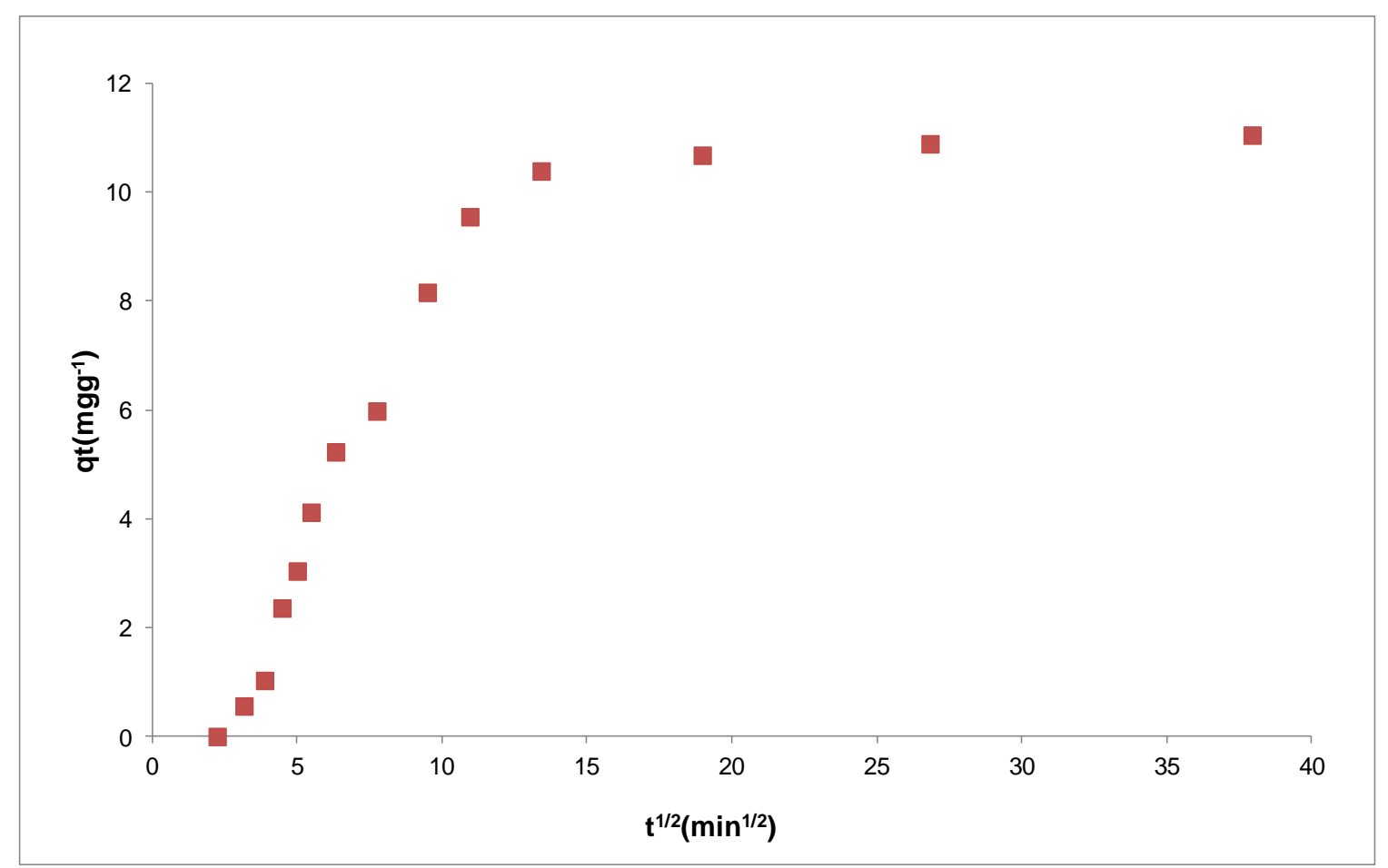

Figure 12: Intraparticle diffusion plot of Cd(II) ion sorption on PTPS residue adsorbent 


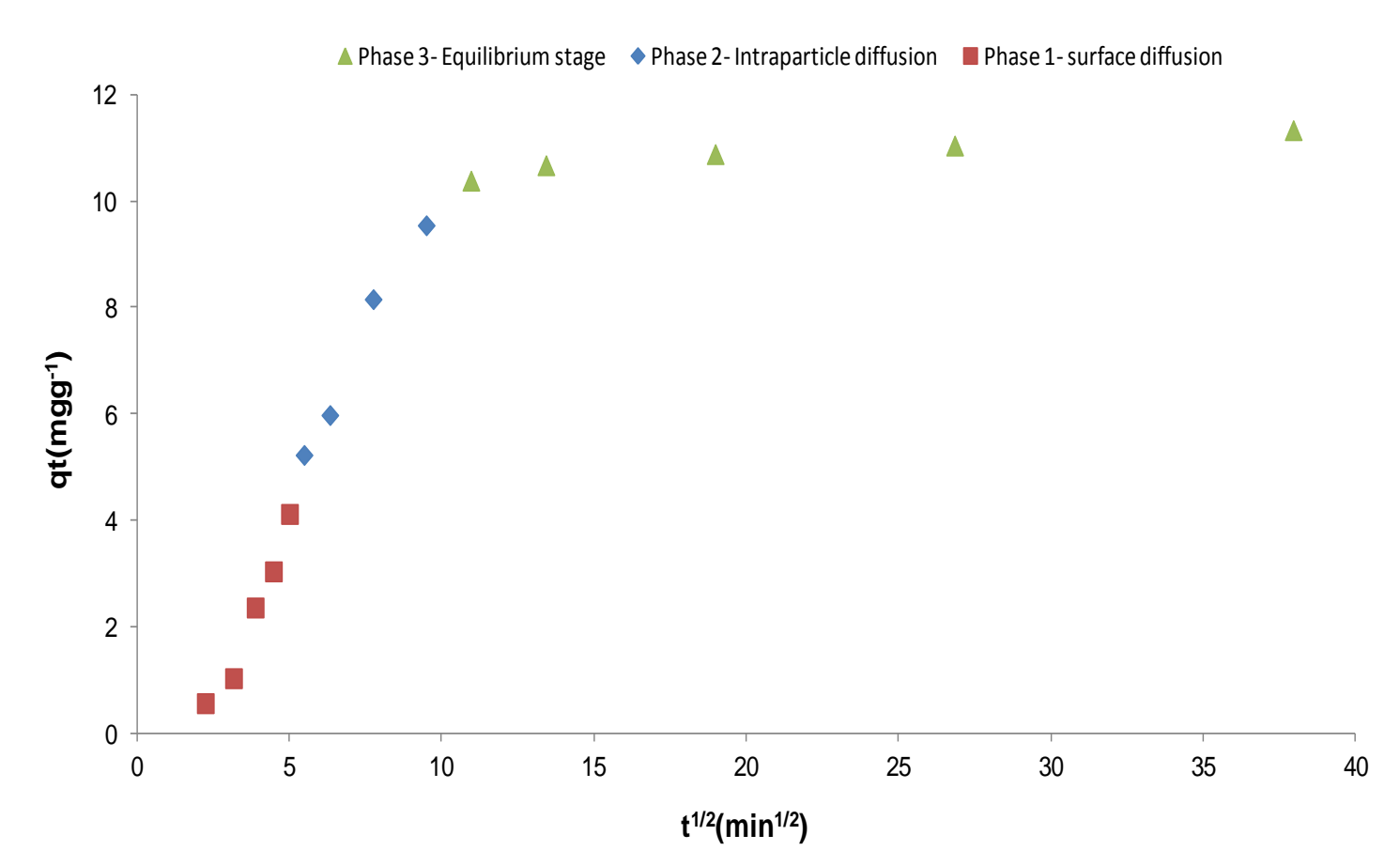

Figure 13: Kinetic stages in intraparticle diffusion plot of Cd(II) ion sorption on PTPS residue

From Figures 12 and 13, it is observed that the intraparticle diffusion plot is made up of 3 linear regions. Hence it is proposed that the sorption of $\mathrm{Cd}(\mathrm{II})$ ions onto the PTPS adsorbent occurred via 3 phases wherein:

- The initial first phase represents the region of external surface diffusion in which film diffusion pre-dominates the kinetics of $\mathrm{Cd}(\mathrm{II})$ uptake and is characterised by the diffusion of the $\mathrm{Cd}(\mathrm{II})$ ions across the boundary layer

- The second phase represents a gradual sorption of the $\mathrm{Cd}(\mathrm{II})$ ions onto the PTPS adsorbent where it is suggested that the intraparticle diffusion of the metal ions within the pores of the adsorbent is rate limiting (Sengil et al.,2009) and

- The third phase is the process associated with the attainment of equilibrium during the sorption process seen as the plateau region wherein the uptake is slowed due to the low $\mathrm{Cd}(\mathrm{II})$ ion concentration in the adsorbate as well as the lower availability of active sites on the PTPS adsorbent for Cd(II) ion uptake and the repulsive interactions existing on the surface of the adsorbent (Basha et al., 2009; Sengil et al.,2009).

From the intraparticle plot and the above observation, phase 2 of the kinetic profile was taken as the region where intraparticle diffusion kinetics dominates and the intraparticle diffusion rate constant for the model $\left(\mathrm{K}_{\mathrm{id}}\right)$ is $1.119 \mathrm{mgg}^{-1} \mathrm{~min}^{-0.5}$. It should be noted that due to the existence of these multiple steps in the rate of $\mathrm{Cd}(\mathrm{II})$ ion uptake and since the intraparticle 
diffusion plot for $\mathrm{Cd}(\mathrm{II})$ ion sorption did not go through the origin, then the diffusion differences in the rate of mass transfer between the initial and final stages of adsorption. However, at each phase of the kinetic profile, it is assumed that only one mechanism was dominant (Fierro et al., 2008; Diagboya et al., 2014; Olu-Owolabi et al., 2014). Furthermore, the boundary layer parameter (C) obtained from the intraparticle diffusion plot is 0.895 and this gives an indication of the effect of the boundary layer thickness on the $\mathrm{Cd}$ (II) ion diffusion. A higher value for $\mathrm{C}$ indicates that there is a greater effect of the boundary layer on metal ion diffusion across the adsorbent surface (Li et al., 2012; Olu-Owolabi et al., 2014). However, the multiple steps that are observed to operate based on the different kinetic models during the kinetics of $\mathrm{Cd}(\mathrm{II})$ ion sorption suggest that there are a number of other factors that have to be taken into consideration in the evaluation of metal ion sorption in an aqueous system. These include the implications of the dilute aqueous system that adsorption is being carried out, the rate of change of adsorbate concentration with time as sorption progresses and the type of mass transport that might occur based on the nature of the adsorbent. All these parameters may in one way or the other influence the transport of the adsorbate ions through the concentration barrier onto the adsorbent surface or active sites and have to be taken into consideration when evaluating the kinetics of sorption.

\subsubsection{Equilibrium Isotherm Modelling}

The interaction in an adsorption system between the adsorbent and the adsorbate is a dynamic process and the quantification of the impact of the adsorbent on the adsorbate is described by the amount of adsorbate that is removed by the adsorbent. This also depends on the loading of the adsorbent. The loading of an adsorbent can be described by an equilibrium isotherm which is characterised by certain constants whose values express the surface properties and affinity of the adsorbent to the adsorbate (Sari et al., 2008). Hence, equilibrium modelling or adsorption isotherms are studied to characterize the equilibrium. In order to represent the equilibrium adsorptive behaviour of the adsorbent-adsorbate interaction, it is important to have a satisfactory description of the equilibrium relationship between the two phases comprising the adsorption system. These equations represent the relationship between the amount of substance adsorbed on the adsorbent and the amount of adsorbate remaining in solution (Athar et al., 2013; El-Ashtoukhy et al., 2008). The adsorption equilibrium data 
indicates the relationship between the mass of the adsorbate sorbed per unit mass of adsorbent $\left(\mathrm{q}_{\mathrm{e}}\right)$ and the adsorbate concentration for the solution at equilibrium $\mathrm{C}_{\mathrm{e}}$ (Sarada et al., 2014).

Two equilibrium isotherm models were used to characterize the removal of $\mathrm{Cd}(\mathrm{II})$ and ion from aqueous solution using the PTPS adsorbent. These were the Langmuir, Freundlich and isotherms. The Langmuir isotherm model has been successfully applied to pollutant biosorption processes and is one of the most widely used isotherm. A basic assumption of the Langmuir isotherm is that sorption takes place at specific sites, which are uniformly distributed across the surface of the adsorbent (Langmuir, 1918; Basha et al., 2009). The model can be written in its non-linear format as:

$$
q_{e}=\frac{q_{m} K_{L} C_{e}}{1+K_{L} C_{e}}
$$

Where $\mathrm{q}_{\mathrm{e}}$ is the equilibrium metal ion concentration on the adsorbent $\left(\mathrm{mgg}^{-1}\right)$,

$\mathrm{C}_{\mathrm{e}}$ is the equilibrium metal ion concentration in the solution $\left(\mathrm{mgl}^{-1}\right)$,

$\mathrm{q}_{\mathrm{m}}$ is the monolayer adsorption capacity of the adsorbent $\left(\mathrm{mgg}^{-1}\right)$ also known as $\mathrm{q}_{\max }$

$\mathrm{K}_{\mathrm{L}}$ is the Langmuir adsorption constant $\left(\mathrm{lmg}^{-1}\right)$ related with the free energy of adsorption (Sari et al., 2008).

The second isotherm model considered in this study was the Freundlich isotherm. The Freundlich isotherm assumes a heterogeneous adsorption surface and active sites with different energy based on multilayer adsorption. The model estimates the adsorption intensity of the adsorbate on an adsorbent (Freundlich, 1906; Athar et al., 2013). The model in its nonlinear form is given as:

$$
q_{e}=K_{F}\left(C_{e}\right)^{1 / n}
$$

Where $\mathrm{K}_{\mathrm{F}}$ is a constant relating to the adsorption capacity $\left(\mathrm{mgg}^{-1}\right)$

$\mathrm{C}_{\mathrm{e}}$ is the concentration of metal ions at equilibrium $\left(\mathrm{mgl}^{-1}\right)$

$1 / \mathrm{n}$ is an empirical parameter relating to the adsorption intensity which varies with the heterogeneity of the material (Sari et al., 2008).

To determine the goodness of fit of the isotherm models to the experimental data using nonlinear regression, the optimization procedure requires that error functions be defined to enable the fitting of the model parameters with the experimental values. In this study, the coefficient 
of determination $\left(r^{2}\right)$, the chi-square test $\left(\chi^{2}\right)$ and the root mean square error (RMSE) for each

\section{Langmuir Isotherm}

For the Langmuir isotherm model, it can be seen that the experimental data were quite in agreement with the isotherm model values with coefficient of determination values of 0.97 for the PTPS adsorbent. This model assumes that there exist a monolayer coverage of the surface of the adsorbent with Cd(II) ions (Athar et al., 2013). From this model, the value of Langmuir constant $\mathrm{K}_{\mathrm{L}}$ obtained was $5.21 \times 10^{-3} \mathrm{lmg}^{-1}$ for the PTPS adsorbent as seen in Table 5. The value of the Langmuir isotherm constant $\mathrm{q}_{\max }$ from the Langmuir isotherm plot is also seen in 
Table 5. This value indicates the maximum monolayer capacity of the adsorbent based on the Langmuir isotherm assumption of a saturated monolayer. It should be noted that the value of the qmax for the PTPS adsorbent is higher than the experimental loading of the adsorbent at the initial concentration of $500 \mathrm{mgl}^{-1}$, which was the maximum initial concentration used in this study. Hence, the isotherm constant $\mathrm{q}_{\max }$ models that maximum adsorption loading (capacity) of the surface of the adsorbent assuming the Langmuir monolayer coverage. This $\mathrm{q}_{\max }$ value is an important parameter that is used to aid the design of adsorption systems when scaling up an adsorption process as it provides information on the maximum saturation capacity of the adsorbent (Rao et al., 2006). From Table 5, it is observed that PTPS had a $\mathrm{q}_{\max }$ value of $18.9 \mathrm{mgg}^{-1}$ implying the amount of the $\mathrm{Cd}(\mathrm{II})$ ion that the adsorbent would be have the capacity to remove from the adsorbate per gram of adsorbent.

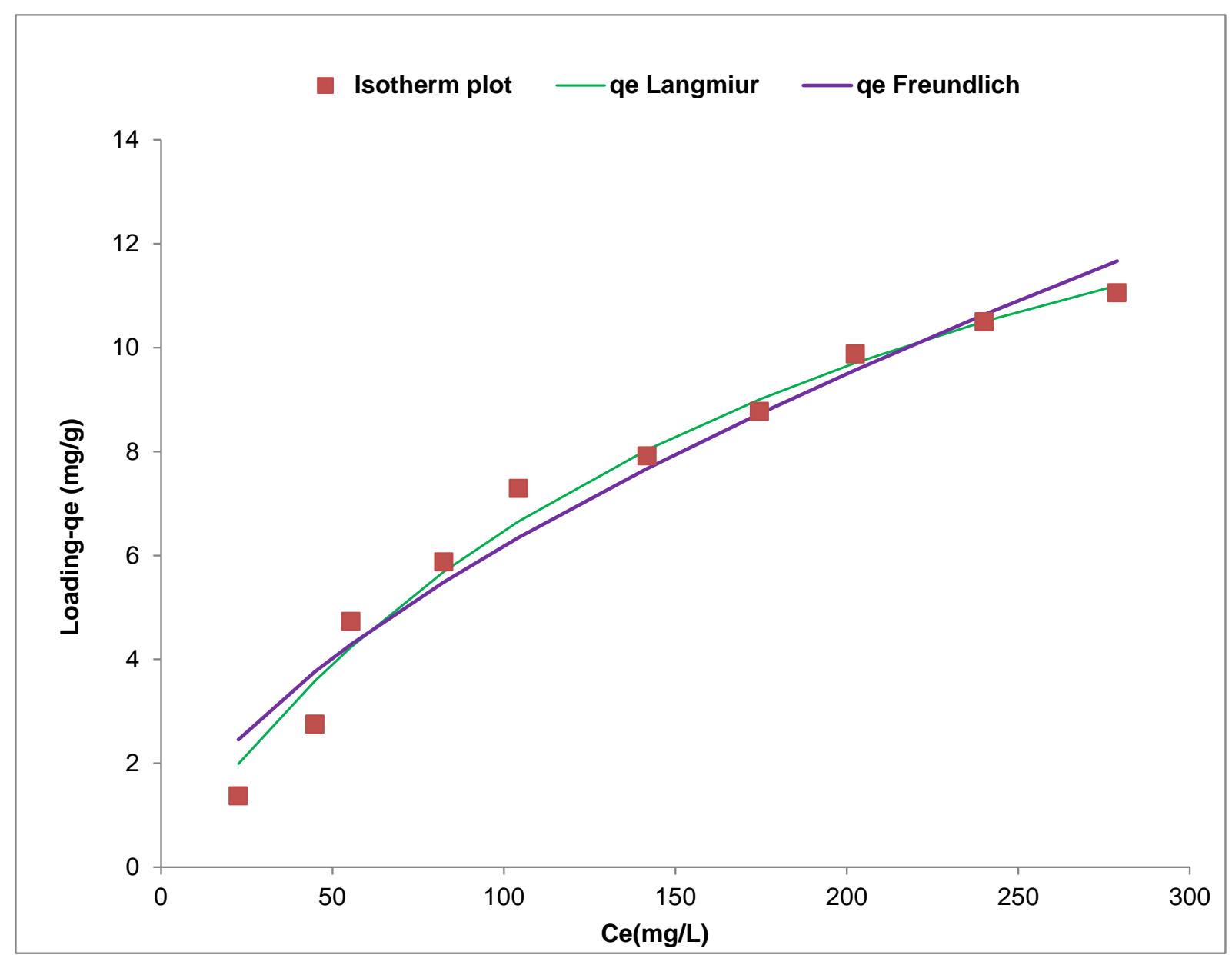

Figure 14: Langmuir and Freundlich equilibrium isotherm modelling for Cd(II) sorption on PTPS residue. 
Table 5: Isotherm model parameters for sorption of Cd(II) onto PTPS adsorbent

\begin{tabular}{lll}
\hline Isotherm Models & Parameters & Values \\
\hline & $\mathrm{q}_{\max }\left(\mathrm{mgg}^{-1}\right)$ & 18.9 \\
& $\mathrm{~K}_{\mathrm{L}}\left(\mathrm{lmg}^{-1}\right)$ & $5.21 \mathrm{E}-03$ \\
Langmuir & $\mathrm{r}^{2}$ & 0.97 \\
& $\chi 2$ & 0.03 \\
& $\mathrm{RMSE}$ & $1.17 \mathrm{E}-01$ \\
& & \\
& & 0.35 \\
& $\mathrm{~K}_{\mathrm{F}}\left(\mathrm{mgg}^{-1}\right)$ & 1.61 \\
& $\mathrm{~N}$ & 0.96 \\
& $\mathrm{r}^{2}$ & 0.06 \\
& $\chi^{2}$ & $2.49 \mathrm{E}-01$ \\
& $\mathrm{RMSE}$ &
\end{tabular}

A characteristic of the Langmuir isotherm can be expressed using a dimensionless constant called "the separation factor" $\mathrm{R}_{\mathrm{L}}$ which is defined as:

$$
R_{L}=\frac{1}{1+K_{L} C_{o}}
$$

where $\mathrm{K}_{\mathrm{L}}$ is the Langmuir constant and $\mathrm{C}_{\mathrm{o}}$ is the initial concentration of cadmium ion in the solution. The value $\mathrm{R}_{\mathrm{L}}$ indicates the shape of the plot as follows:

$\mathrm{R}_{\mathrm{L}}=>1 \quad$ Unfavourable

$\mathrm{R}_{\mathrm{L}}=1 \quad$ Linear

$0<\mathrm{R}_{\mathrm{L}}<1 \quad$ Favourable

$\mathrm{R}_{\mathrm{L}}=0 \quad$ Irreversible (Siswoyo et al., 2014)

The plot of the separation factor for the Langmuir isotherm for the PTPS adsorbent is shown in Figure 15. From the plot it is observed that the value of the separation factor $\left(R_{L}\right)$ for initial cadmium ion concentration ranged from $0.79\left(50 \mathrm{mgL}^{-1}\right)$ to $0.27\left(500 \mathrm{mgL}^{-1}\right)$ thereby indicating that the adsorption of $\mathrm{Cd}(\mathrm{II})$ ions by the PTPS adsorbent was favourable. 
Table 6: $\mathrm{Cd}(\mathrm{II})$ Langmuir constant $\mathrm{q}_{\max }$ of this study with those reported in literature

\begin{tabular}{lll} 
Adsorbent & $\mathrm{q}_{\max }\left(\mathrm{mgg}^{-1}\right)$ & Reference \\
\hline Rice husk & 16.7 & Krishnani et al., 2008 \\
Rape straw & 17.53 & Gong, 2013 \\
Sunflower (Helianthus annuus) & 14.9 & Feizi and Jalali, 2015 \\
Canola (Brassica napus) & 14.7 & Feizi and Jalali, 2015 \\
Walnut Shell(Juglans regia) & 8.3 & Feizi and Jalali, 2015 \\
Potato (Solanum tuberosum) & 14.3 & Feizi and Jalali, 2015 \\
Caulerapa fastigiata & 16.48 & Sarada et al., 2014 \\
Teak leaf powder & 29.94 & Rao et al., 2010 \\
Juniper fibre & 9.2 & Min et al., 2004 \\
Coconut copra meal & 5.1 & Ho and Ofomaja, 2006 \\
Pinus sylvestris sawdust & 19.1 & Taty-Costodes et al., 2003 \\
Kiwi cortex & 15.9 & Al-Qahtani, 2016 \\
Carica papaya wood & 17.4 & Saeed et al., 2005 \\
Glebionis Coronaria L. & 18.3 & Tounsadi et al., 2015 \\
Sweet potato peels (PTPS) & 18.9 & This study \\
\hline
\end{tabular}

\section{Freundlich Isotherm}

The Freundlich isotherm model differs from the Langmuir model because it assumes a heterogeneous adsorption surface with active sites with different energy thereby implying a multilayer surface coverage whereas the Langmuir model assumes a homogenous surface with monolayer coverage. The Freundlich isotherm plots for the PTPS adsorbent is also shown in Figure 14. From this plot, the isotherm constants and coefficient of determination $\left(r^{2}\right)$ for Cd(II) sorption was obtained and presented in Table 5. The values obtained for the $r^{2}$ indicate a close proximity of the model with the experimental data even though the data obtained for the Langmuir model were better. However, the $\mathrm{r}^{2}$ values were still an indication of a good fit with experimental values with a value of 0.96 . The value of the Freundlich isotherm constant " $n$ " which describes the adsorption intensity of the adsorbents also shown in Table 5 and this was also obtained from the Freundlich isotherm. For the PTPS adsorbent this value was 1.61 and indicates that the adsorption of $\mathrm{Cd}(\mathrm{II})$ ions by the PTPS adsorbent was favourable. According to Sarada et al., (2014) a Freundlich isotherm constant "n" value between 1 and 10 indicates that the adsorption intensity is favourable. This parameter has been reported to vary with the heterogeneity of the adsorbent material (Sari et al., 2008). Furthermore, the value of the Freundlich constant " $\mathrm{K}_{\mathrm{F}}$ " which relates to the adsorption 
capacity for a multilayer system is also presented in Table 5. The value of $\mathrm{K}_{\mathrm{F}}$ obtained for the

\subsubsection{Mechanism of $C d(I I)$ ion sorption}

The application of adsorbents for the removal of metal ions from aqueous systems is carried out using a wide range of materials however the process by which these adsorbents remove metal ions from aqueous systems is still not fully understood. This is due to the complex nature of adsorbent surfaces and the different interactions that exist between an adsorbent and an adsorbate during sorption. A number of possible mechanisms have been proposed in literature and these involve an integrative effect of different interactions such as; electrostatic attraction-hydrogen bonding, ion-exchange, physical adsorption, chemisorption, surface complexation and/or precipitation (Tan et al., 2015; Nguyen et al., 2013). According to Krishnan and Anirudhan (2003), during the sorption of the metal ions, the ability of sorption to proceed will depend on the $\mathrm{pH}$ and the type of species that exist at this condition. In the present study the dominant species of the $\mathrm{Cd}(\mathrm{II})$ ions in solution at $\mathrm{pH}>8.0$ is the hydroxide $\left\{\mathrm{Cd}(\mathrm{OH})_{2}\right\}$. At $\mathrm{pH}<8.0$ the dominant metal species are of the type $\mathrm{Cd}^{2+}$ and $\mathrm{Cd}(\mathrm{OH})^{+}$. The interaction of these metal ion species with the species in solution and the adsorbent surface will therefore affect the amount that is preferentially adsorbed onto the surface of the adsorbents. The highest loading on the PTPS residue was observed to occur at $\mathrm{pH} 7$ and this $\mathrm{pH}$ was close to that chosen based on the zeta potential analysis of the residue (6.5). Thus, the adsorption of the $\mathrm{Cd}(\mathrm{II})$ ions at this optimum $\mathrm{pH}$ may be due to the interaction of the species that are dominant at $\mathrm{pH}<8$, such as $\mathrm{Cd}^{2+}$ and $\mathrm{Cd}(\mathrm{OH})^{+}$and with the functional groups on the adsorbents surface.

Infra-red spectra evidence of adsorbents after metal ion sorption has been used in a number of studies to confirm the participation of hydroxyl, carbonyl, phenolic functional groups found on the surface or carbon adsorbents in metal ion sorption (Barkar et al., 2013; Ding et al., 2014). According to Bailey et al., (1999), phenolic groups are believed to be accountable for 
the formation of complexes with heavy metal ions during sorption and evidence from infrared spectroscopy has been used to confirm this mechanism of sorption. Barkar et al., (2013) in their study on the sorption of $\mathrm{Cd}(\mathrm{II})$ ions using dried cactus observed a decrease in the wave number of asymmetric stretching of the carboxylic double bond in the unloaded dried cactus when compared to those of the metal ion loaded cactus. This shift in band was used to conclude that the carboxylic acid groups were likely responsible for the binding of $\mathrm{Cd}(\mathrm{II})$ by the dried cactus biosorbent. This inference can also be applied in the present study from the evidence the infra-red spectra observed in the sorption of $\mathrm{Cd}(\mathrm{II})$ onto the residue adsorbent shown in Figures 7 and 8 in this study. Thus it can be proposed that there was a complexation reaction between the functional groups on the PTPS adsorbent and the Cd(II) ions leading to proton $\left(\mathrm{H}^{+}\right)$elimination into the adsorbate. This proton $\left(\mathrm{H}^{+}\right)$effect was observed in the studies on the effect of $\mathrm{pH}$ on $\mathrm{Cd}(\mathrm{II})$ ion studies with an increase in the final $\mathrm{pH}$ of the adsorbate after metal ion sorption. Such a decrease in $\mathrm{pH}$ after sorption indicates the displacement of the protons $\left(\mathrm{H}^{+}\right)$from the adsorbent matrix by the $\mathrm{Cd}(\mathrm{II})$ ion which leads to a reduction in the adsorbate $\mathrm{pH}$.

A further mechanism that can be used to describe the uptake of $\mathrm{Cd}(\mathrm{II})$ ions is that of ionexchange from the evidence obtained from the EDAX analysis (Figs.4 \& 5). The EDAX analysis of the residue adsorbent used in this study when compared to those of the fresh adsorbent showed a decrease in the percentages of some elements such as molybdenum, aluminium and calcium in the matrix of the used adsorbent with corresponding increase in the percentage of $\mathrm{Cd}(\mathrm{II})$ ions, thus implying that the loading of the $\mathrm{Cd}(\mathrm{II})$ ion may also proceed via an ion-exchange mechanism. This mechanism has also been observed by Swiatkowski et al., (2004) for the removal of $\mathrm{Pb}$ (II) on activated carbon surfaces. In their study they reported that the approach of using ion-exchange and acid-based properties of a carbon surface alone to explain the interactions leading to metal ion uptake in an adsorption system is insufficient as there are different interactions that operate in this aqueous system. Hence the mechanism by which the PTPS adsorbent interacts with metal ion adsorbate can be inferred from the infra-red, EDAX and $\mathrm{pH}$ studies to be combinations of ion-exchange, surface complexation, chemisorption and electrostatic interactions. 


\section{Conclusion}

In this work, an experimental study on the utilisation of sweet potato peels (PTPS), an abundantly available agricultural residue for the removal of $\mathrm{Cd}(\mathrm{II})$ ions from aqueous solution was carried out. The effect of a number of parameters such as $\mathrm{pH}$, contact time and initial metal ion concentration on the loading of the metal ion onto the adsorbent were determined. The results showed that the loading of $\mathrm{Cd}(\mathrm{II})$ ions $\left(\mathrm{mgg}^{-1}\right)$ increased with increase in initial metal ion concentration, time and $\mathrm{pH}$ and the optimised $\mathrm{pH}$ range for adsorption was from 6.5 to 7. The kinetics of $\mathrm{Cd}(\mathrm{II})$ ion removal indicated an optimum contact time of 180 minutes via a two stage kinetic uptake profile(initial fast and subsequent slow equilibrium). Kinetic modelling of $\mathrm{Cd}(\mathrm{II})$ ion adsorption was carried out using the pseudo first order (PFO), pseudo-second order (PSO) and intraparticle diffusion models. The PFO and PSO were evaluated using a non-linear optimization procedure and the PFO described the kinetics better than the PSO order model. The results from the intraparticle modelling suggest that intraparticle diffusion mechanism was not the only rate controlling step for the sorption Cd(II) ions by the PTPS adsorbent. The physico-chemical, elemental and spectroscopic properties of the PTPS residue adsorbent were determined and the results obtained from the spectroscopic analysis using (FTIR analysis and EDAX) indicates that ion-exchange and adsorptioncomplexation mechanism may be involved in the loading of the $\mathrm{Cd}(\mathrm{II})$ ions onto the PTPS adsorbent. The equilibrium sorption studies of $\mathrm{Cd}(\mathrm{II})$ ions were modelled using the Langmuir and Freundlich isotherms using a non-linear optimization approach and the experimental data was described better by the Langmuir model. This indicates that the monolayer adsorption capacity of the PTPS adsorbent was $18.9 \mathrm{mgg}^{-1}$ and a Langmuir constant of $5.21 \times 10^{-3} \mathrm{lmg}^{-1}$ at $25{ }^{\circ} \mathrm{C}$ implying that the adsorbent was effective for $\mathrm{Cd}(\mathrm{II})$ ion removal from an aqueous system as well as natural water bodies and effluents. The results of this study highlights the potential of using an agricultural waste residue as an adsorbent for $\mathrm{Cd}(\mathrm{II})$ ion adsorption and has also enabled comparisons to be made with similar adsorbents based on waste biomass. 


\section{References}

Abia, A.A.; Asuquo, E.D. and Orike, D.B (2007) Surface transport kinetic models for $\mathrm{Pb}^{2+}$ sorption, using unmodified and mercaptoacetic acid modified agricultural-by products. European Journal of Scientific Research, 16(2): 303-316.

Abia, A.A. and Asuquo, E.D. (2007) Kinetics of $\mathrm{Cd}^{2+}$ and $\mathrm{Cr}^{3+}$ sorption from aqueous solutions using mercaptoacetic acid modified oil palm fruit fibre (Elaeis guineensis) adsorbents. Tsinghua Science \& Technology, 12(4): 485-492.

Abia, A.A; Didi, O.B. and Asuquo, E.D. (2006) Modelling of $\mathrm{Cd}^{2+}$ sorption kinetics onto some thiolated agricultural waste adsorbents. Journal of Applied Sciences, 6(12):2549-2556.

Abia, A.A; Horsfall, M. Jnr and Didi, O. (2003) The use of chemically modified and unmodified cassava waste for the removal of $\mathrm{Cd}, \mathrm{Cu}$ and $\mathrm{Zn}$ ions from aqueous solution. Bioresource Technology, 90:345-348.

Ahmadi, K.; Ghaedi, M. and Ansari,A.(2015) Comparison of nickel doped zinc sulphide and/or palladium nanoparticle loaded on activated carbon as efficient adsorbents for kinetic and equilibrium study of removal of Congo Red dye. Spectrochimica Acta Part A: Molecular and Biomolecular Spectroscopy, 136:1441-1449.

Ahmed, M.J.K.; Ahmaruzzaman, M. and Reza, R.A.(2014) Lignocellulosic-derived modified agricultural waste: Development, characterisation and implementation in sequestering pyridine from aqueous solutions. Journal of Colloid and Interface Science, 428:222-234.

Alimohammadi, N.; Shadiazadeh, S.R. and Kezeminezhadi, I.(2013) Removal of cadmium ion from drilling fluid using nano-adsorbent. Fuel, 111: 505-509.

Alkan, M.; Demirbaş, Ö. and Doğan, M., (2007) Adsorption kinetics and thermodynamics of an anionic dye onto sepiolite. Microporous and Mesoporous Materials, 101(3): 388-396.

Al-Qahtani, K.M.(2016) Water purification using different waste fruit cortexes for the removal of heavy metals, Journal of Taibah University for Science, Available http://dx.doi.org/10.1016/j.jtusci.2015.09.001. 
Amouei, A I.; Amooey, A.A. and Asgharzadeh, F. (2013) Cadmium removal from aqueous

Antunes, W.M.; Luna, A.S.; Henriques, C.A. and Costa, A.C.A.(2003) An evaluation of copper biosorption by a brown seaweed under optimized conditions. Electronic Journal of Biotechnology,6(3).Available internet:

http://www.scielo.cl/scielo.php?script=sci_arttext\&pid=S0717-34582003000300003 Accessed on 10/10/2015.

AOAC (2000) Official Methods of Analysis. Horwitz, W(ed), $17^{\text {th }}$ Ed. Association of Official Analytical Chemist. Gaithersburg MD. Publishers, Virginia, USA.

Athar, M.; Farooq, V.; Aslam, M. and Salam, M. (2013) Adsorption of Pb(II) ions onto biomass from Trifolium resupinatum: equilibrium and kinetic studies. Applied Water Science, 3: 665-672.

Augustine, A.A.; Orike, B.D. and Edidiong, A.D. (2007) Adsorption kinetics and modelling of $\mathrm{Cu}$ (II) ion sorption from aqueous solution by mercaptoacetic acid modified cassava (manihot sculenta cranz) wastes. Electronic Journal of Environmental, Agricultural and Food Chemistry, 6(4):2221-2234

Azarudeen, R.S.; Ahmed, M.A.R.; Subha, R. and Burkanudeen, A.R. (2015) Heavy and toxic metal ion removal by a novel polymeric ion-exchanger: Synthesis, characterisation, kinetics and equilibrium. Journal of Chemical Technology Biotechnology, 90:2170-2179.

Bailey, S. E.; Olin, T. J.; Bricka, M. R.; Adrian, D. D. (1999) A review of potentially low-cost sorbents for heavy metals. Water Research, 3(11): 2469-2479.

Barkar, N.; Abdennouri, M.; El Makhfouk, M. and Qourzal, S. (2013) Biosorption characteristics of cadmium and lead onto eco-friendly dried cactus (opuntia ficus indica) cladodes. Journal of Environmental Chemical Engineering 1: 144-149.

Basha, S.; Murthy, Z.V.P and Jha, B. (2009) Sorption of $\mathrm{Hg}(\mathrm{II})$ onto Carica papaya; Experimental studies and design of batch sorber. Chemical Engineering Journal, 147:226234. 
Basso, M. C.; Cerrella, E. G. and Cukierman, A. L. (2002) Lignocellulosic materials as potential biosorbents of trace toxic metals from wastewater. Industrial Engineering Chemistry Research, 41: 3580-3585.

Bernard, A. (2008) Cadmium and its adverse effects on human health. Indian Journal of Medical Research, 128:557-564.

Bodirlau, R.; Teaca, C.A. and Spiridon, I. (2009) Preparation and characterisation of composites comprising modified hardwood and wood polymers/poly (vinyl chloride). Bioresources, 4 (4):1285-1304.

Boparai, K.H; Joseph, M.and O’Carroll, D.M. (2011) Kinetics and thermodynamics of cadmium ion removal by adsorption onto nano zerovalent iron particles. Journal of Hazardous Materials, 186(1):458-465.

Bota, A.; Laszlo, K.; Nagy, L.G.; Subklew, G.; Schlimper, H. and Schwuger, M.L. (1996) Adsorbents from waste materials. Adsorption, 3:81-91.

Ceribasi, H.I. and Yetis, U. (N 2001) Biosorption of Ni (II) and Pb(II) by Phanaerochate chrysosporium from binary metal system-kinetics. Water SA, 27(1):15-20.

Chang, Y. M.; Tsai W.T.; Li, M.H. and Chang, S.H. (2015) Preparation and characterization of porous carbon material from post-extracted algal residue by a thermogravimetric system. Algal Research, 9: 8-13.

Cheung, C.W.; Porter, J.F. and McKay.(2000) Sorption kinetic analysis for the removal of cadmium ions from effluents using bone char. Water Research, 35(3):605-612.

Coleman N. T., McClung A. C. and Moore D. P. (1956) Formation constants for Cu(II)-peat complexes. Science, 123, 330-331.

De Haro-Del Rio, D.A; Al-Joubori, S.; Kontogiannis,O.; Papadatos-Gigantes, D.; Ajayi, O.; Li, C. and Holmes, S.M. (2015) The removal of caesium ions using supported clinoptilolite. Journal of Hazardous Materials, 289:1-8. 
Diagboya, P. N; Olu-Owolabi, B. I. and Adebowale, K.O.(2014) Microscale scavenging of pentachlorophenol in water using amine and tripolyphosphate-grafted SBA-15 silica: Batch and modeling studies, Journal of Environmental Management, 146, : 42-49.

Ding, W.; Dong, X.; Ime, I. M.; Gao, B and Ma, L. Q. (2014) Pyrolytic temperatures impact lead sorption mechanism by bagasse biochars. Chemosphere, 105: 68-74.

Dubey, S. P. and Gopal, K. (2006) Adsorption of Chromium (VI) on low-cost adsorbents derived from agricultural materials: a comparative study. Journal of Hazardous Materials, 145: 467-470.

Egbe, M. O.; Afuape, S. O. and Idoko, J. A. (2012) Performance of Improved Sweet Potato (Ipomea batatas L.) varieties in Makurdi, Southern Guinea Savanna of Nigeria. American Journal of Experimental Agriculture, 2(4): 573-58.

El-Ashtoukhy, E-S. Z.; Amin, N. K. and Abdelwahab, O. (2008) Removal of lead (II) and copper (II) from aqueous solution using pomegranate peel as a new adsorbent. Desalination 223:162-173.

El-Khaiary, M.I.; Malash, G.F. and Ho, Y.S. (2010) On the use of linearized pseudo-secondorder kinetic equations for modeling adsorption systems, Desalination, 257(1-3):93-101

Fan, M.; Dai, D. and Huang, B. (2012). Fourier Transform Infrared Spectroscopy for Natural Fibres, Fourier Transform - Materials Analysis, Salih S.M. (Ed.).InTech, DOI: 10.5772/35482. Available Internet: http://www.intechopen.com/books/fourier-transformmaterials-analysis/fourier-transform-infrared-spectroscopy-for-natural-fibres $\quad$ Accessed $12 / 02 / 2015$.

FAO (1998) Storage and Processing of Roots and Tubers in the Tropics-Food and Agricultural Organisation, Calverley, D.J.B.(Ed).Available internet: http://www.fao.org/docrep/x5415e/x5415e01.htm Accessed on 11/09/2015.

FAOSTAT (2015) Food and Agricultural Organisation of the United Nations Statistics Division. Available internet: http://faostat3.fao.org/browse/Q/QC/E Accessed 12/4/201.5 
Farooq, U.; Khan, M.A; Athar, M. and Kozinski, J.A.(2011)Effect of modification of environmentally friendly adsorbent wheat (Triticum aestivum) on the biosorption removal of cadmium(II) ions from aqueous solution. Chemical Engineering Journal, 171:400-410.

Feizi, M. and Jalali, M.(2015) Removal of heavy metals from aqueous solutions using sunflower, potato, canola and walnut shell residues, Journal of the Taiwan Institute of Chemical Engineers, 54:125-136

Fernandez, M. E.; Ledesma, B.; Roman, S.; Bonelli, P. R. and Cukierman, A. L. (2015) Development and characterization of activated hydrochars from orange peels as adsorbents for emerging organic contaminants. Bioresource Technology, 183: 221-228.

Fierro, V.; Torné-Fernández, V.; Montané, D.; Celzard, A.(2008) Adsorption of phenol onto activated carbons having different textural and surface properties, Microporous and Mesoporous Materials,111(1-3): 276-284.

Foroughi-dahr, M.; Abolghasemi, H.; Esmaieli, M.; Nazari, G. and Rasem, B. (2015) Experimental study on the adsorptive behaviour of Congo red in cationic surfactant-modified tea waste. Process Safety and Environmental Protection, 95: 226-236.

Freundlich, H. M. F. (1906) Over the Adsorption in Solution. Journal Physical Chemistry, 57: $385-471$.

Gautam, R. K.; Mudhoo, A.; Lofrano, G.; Chattopadhyaya, C. M. (2014) Biomass-derived biosorbents for metal ions sequestration: Adsorbent modification and activation methods and adsorbent regeneration. Journal of Environmental Chemical Engineering, 2: 239-259.

Giwa, A.A.; Bello, I.A.; Oladipo, M.A. and Adeoye, D.O.(2013) Removal of cadmium from wastewater by adsorption using the husk of melon (Citrullus lanatus) seed. International Journal of Basic and Applied Science, 2(1):110-123.

Giles, C.H.; MacEwan, T.; Nakhwa, S. and Smith, D. (1960) Studies in adsorption. Part XI. A system of classification of solution adsorption isotherm and its use in the diagnosis of adsorption mechanism and in measurement of specific surface areas of solids. Journal of Chemical Society, 3973-3993.

Gong, X. (2013) Kinetic and Equilibrium Studies on the Adsorption of $\mathrm{Pb}(\mathrm{II}), \mathrm{Cd}(\mathrm{II})$ and $\mathrm{Cu}(\mathrm{II})$ by Rape Straw. Adsorption Science and Technology, 31(6): 559-571. 
Guo, J. and Lua, A. C. (2000) Adsorption of sulfur dioxide onto activated carbons prepared from oil-palm shells impregnated with potassium hydroxide. Journal of Chemical Technology and Biotechnology, 75(11):971-976.

Guo, J. and Lua, A. C. (2002) Characterization of adsorbent prepared from oil-palm shell by $\mathrm{CO}_{2}$ activation for removal of gaseous pollutants. Material Letters, 55: 334-339.

Gurses A., Hassani A., Kıransan M., Acıslı O. and Karaca S. (2014) Removal of methylene blue from aqueous solution using by untreated lignite as potential low-cost adsorbent: Kinetic, thermodynamic and equilibrium approach, Journal of Water Process Engineering, 2 10-21.

Ho, Y.S. (2004a) Citation review of Lagergren kinetic rate equation on adsorption reactions. Scientometrics, 59(1):171-177.

Ho, Y.S. (2004b) Selection of optimum sorption isotherm. Carbon, 42: 2115-2116.

Ho, Y. S. (2006) Review of second-order models for adsorption systems. Journal of Hazardous Materials, B 136: 681-689.

Ho, Y. S. and Chiang, C. C. (2001) Sorption studies of acid dye by mixed sorbents. Adsorption, 7: 139-147.

Ho, Y. S.; Chiu, W. T.; Hsu, C. S.; Huang, C. T. (2004) Sorption of lead ions form aqueous solution using tree fern as a sorbent. Hydrometallurgy, 73: 55-61.

Ho, Y.S.; Huang, C.T. and Huang, H.W (2002) Equilibrium sorption isotherm for metal ions on tree fern. Process Biochemistry, 37(12):1421-1430.

Ho, Y. S. and McKay,G. (2000) The Kinetics of sorption of divalent metal ions onto sphagnum moss peat. Water Research, 34: 735-742.

Ho, Y. S. and McKay,G.(1998) A comparison of chemisorption kinetic models applied to pollutant removal on various sorbents. Process Safety and Environmental Protection, 76(4):322-340.

Ho, Y. S. and McKay,G.(1999) Pseudo-second order model for sorption processes. Process Biochemistry, 34(5): 451-465. 
Ho, Y. S. and McKay,G (2004) Sorption of copper(II) from aqueous solution by peat. Water, Air, and Soil Pollution, 158:77-97.

Ho, Y. S. and Ofomaja, A. E. (2006) Biosorption thermodynamics of Cadmium on coconut copra meal as biosorbent. Biochemical Engineering Journal, 30: 117-123.

Horsfall, M.; Spiff, A. I. (2005) Sorption of lead, cadmium and zinc on sulphur-containing chemically modified wastes of fluted pumpkin (Telfairia Occidentalis Hookf.). Chemistry and Biodiversity, 2(3): 373-385.

Hossain, A.; Bhattacharyya, S.R. and Aditya, G. (2015) Biosorption of cadmium by waste shell dust of fresh water mussel-Lamellidens marginalis: Implications for metal Bioremediation. ACS Sustainable Chemistry \& Engineering, 3:1-8.

Hossain, A.M.; Ngo, H.H. and Guo, W. (2013) Introductory of Microsoft excel SOLVER function-Spread sheet method for isotherm and kinetics modelling of metals biosorption in water and wastewater. Journal of Water Sustainability, 3 (4):223-237.

Igwe, J. C. and Abia, A. A. (2007) Adsorption kinetics and intraparticulate diffusivities for bioremediation of $\mathrm{Co}$ (II ), $\mathrm{Fe}$ (II) and $\mathrm{Cu}$ (II) ions from wastewater using modified and unmodified maize cob. International Journal of Physical Science, 2(5): 119-127.

Ipeaiyeda, A.R. and Onianwa, C. P. (2011) Pollution effects of food and beverages effluents on the Alaro River in Ibadan city, Nigeria. Bulletin Chemistry Society Ethiopia, 25(3): 347360.

Iqbal, M.; Schiewar, S. and Cameron, R. (2009) Mechanistic elucidation and evaluation of biosorption of metal ions by grapefruit peel using FTIR spectroscopy, kinetics and isotherms modeling, cations displacement and EDX analysis. Journal of Chemical Technology Biotechnology, 84 (10): 1516-1526.

Jiang, R,; Tian, J.; Zheng, H.; Qi, J.; Sun,S. and Li,X.(2015) A novel magnetic adsorbent based on waste litchi peels for removing $\mathrm{Pb}(\mathrm{II})$ from aqueous solution. Journal of Environment Management, 155:24-30. 
Johari, K.; Saman, N.; Song, S.T. and Mat, H. (2015) Adsorption equilibrium and kinetics of elemental mercury onto coconut pith. Journal of Environmental Science and Technology, 8(2):74-82.

Johri, N.; Jacquillet, G. and Unwin, R. (2010) Heavy metal poisoning: The effects of cadmium on the kidney. Biometals, 23:783-792.

Kakalanga, S.J.; Jabulani, X.B.; Olutoyin, O.B. and Uteiyin, O.O.(2012) Screening of agricultural waste for $\mathrm{Ni}(\mathrm{II})$ adsorption: kinetics, equilibrium and thermodynamic studies. International Journal of Physical Sciences, 7(17):2525-2538.

Khor, K. H.; Zainal, A. and Lim, K. O. (2009) Laboratory-Scale Pyrolysis of Oil Palm Pressed Fruit Fibres. Journal of Oil Palm Research, 21: 577-587.

Krishnan, K. A.; Anirudhan, T. S. (2003) Removal of cadmium (II) from aqueous solution by steam-activated sulphurised carbon prepared from sugar-cane bagasse pith: kinetics and equilibrium studies. Water $S A, 29(2)$ : 147-156.

Krishnani, K. K.; Meng, X.; Christodoulatos, C. and Boddu, V.M. (2008) Biosorption mechanism of nine different heavy metals onto biomatrix from rice husk. Journal of Hazardous Materials, 153: 1222-1234.

Kumar, P.; Singh, H.; Kapur, M.; Mondal, M.J. (2014) Comparative study of Malathion removal from aqueous solution by agricultural and commercial adsorbents. Journal of Water Process Engineering, 3: 67-73.

Lacerda, V.S.; Lopez-Sotelo, J.B.; Correa-Guimaraes, A.; Hernandez-Navarro, S.; SanchezBascones, M.; Navas-Gracia, L.M.; Martin-Ramos, P. and Martin-Gil, J. (2015) Rhodamine B removal with activated carbons obtained from lignocellulosic waste. Journal of Environmental Management, 155:67-76.

Lagergren, S. (1898) About the theory of so-called adsorption of soluble substances. Kungliga Svenska Vetenskapsakademiens. Handlingar, Band 24, No. 4, 1-39.

Langmuir, I. (1918) The adsorption of gases on plane surfaces of glass, mica and platinum. Journal of American Chemical Society, 40: 1361-1403. 
Li, Y.; Du, Q.; Liu, T.; Sun, J.; Jiao, Y.; Xia, Y.; Xia, L.; Wang, Z.; Zhang,W. Wang, K.;

Zhu, H. and Wu, D.(2012) Equilibrium, kinetic and thermodynamic studies on the adsorption of phenol onto graphene. Materials Research Bulletin, 47(8):1898-1904.

Lin, J. and Wang, L. (2009) Comparison between linear and non- linear forms of first-order and pseudo-second order adsorption kinetic models for the removal of methylene blue by activated carbon. Frontiers of Environmnetal Science \& Engineering in China, 3(3): 320-324.

Loukidou, M.X.; Zouboulis, A.I.; Karapantsios, T.D. and Matis, K.A.(2004) Equilibrium and kinetic modelling of chromium(VI) biosorption by Aeromonas Caviae. Colloids and Surfaces A: Physicochemical and Engineering Aspects, 242, (1-3): 2 93-104.

Malbrunot, P.; Vidal, D. and Vermesse, J. (1997) Adsorbent Helium Density Measurement and Its Effect on Adsorption Isotherms at High Pressure. Langmuir, 13:539-544.

Martin-Lara, M.A.; Blazquez, G.; Ronda, A.; Perez, A. and Calero, M. (2013) Development and characterisation of biosorbents to remove heavy metals from aqueous solutions by chemical treatment of Olive stone. Industrial \& Engineering Chemistry Research, 52: 1080910819.

Meitei, M.D. and Prasad, M.N.V. (2013) Lead (II) and Cadmium (II) biosorption on Spirodela polyrhiza (L) Schleiden biomass. Journal of Environmental Chemical Engineering, 1: 200-207.

Menendez-Diaz, J.A. and Martin-Gullon, I. (2006) Types of carbon adsorbents and their production. In: Bandosz,T.J.(Ed), Activated Carbon Surfaces in Environmental Remediation, Elsevier, New York, pp. 1-47.

Min, S.H.; Han, J.S.; Shin, E.W. and Park, J.K. (2004) Improvement of cadmium ion removal by base treatment of Juniper fiber. Water Research, 38: 1289-1295.

Mishra, P.C and Patel, R.K. (2009) Removal of lead and zinc ions from water by low cost adsorbents. Journal of Hazardous Materials, 168:319-325. 
Miyake, Y.; Ishida, H.; Tanaka, S. and Kolev, S.D. (2013) Theoretical analysis of the pseudosecond order kinetic model of adsorption, application to adsorption of $\operatorname{Ag}(\mathrm{I})$ to mesoporous silica microspheres functionalized with thiol groups. Chemical Engineering Journal, 218:350357.

Naiya, T.K.; Singha, B. and Das, S.K.(2011) FTIR study for the Cr(VI) removal from aqueous solution using rice waste. International Conference on Chemistry and Chemical Process-IPCBEE, 10:114-119.

Nguyen, T. A. H.; Ngo, H. H.; Guo, W. S.; Zhang, J.; Liang, S.; Yue, Q. Y.; Li, Q. and Nguyen, T. V. (2013) Applicability of agricultural waste and by-products for adsorptive removal of heavy metals from wastewater. Bioresource Technology, 148: 574-583.

Nomanbhay, S. M.; and Palanisamy, K. (2005) Removal of Heavy Metal from industrial Wastewater using chitosan coated oil palm shell charcoal. Electronic Journal of Biotechnology, 8(1): 43-53.

Odetoye, T.E.; Onifade, K,R.; AbuBakar, M.S. and Titiloye, J.O (2014) Pyrolysis of Parinari polyandra Benth fruit shell for bio-oil production. Biofuel Research Journal, 3: 85-90.

Ojedokun, A.T. and Bello, O.S. (2015) An overview of Low cost adsorbents for copper(II) ions removal. Biotechnology \& Biomaterials, 5:163. DOI:10.4172/2155-952X.1000163.

Oladayo, A. (2010) Proximate composition of some agricultural wastes in Nigeria and their potential use in activated carbon production. Journal of Applied Sciences and Environmental Management, 14(1):55-58.

Olagunju, F. I.; Fakayode, S. B.; Babatunde, R.O. and Ogunwole-Olapade, F. (2013) Gender Analysis of Sweet Potato Production in Osun State, Nigeria. Asian Journal of Agricultural Extension, Economics \& Sociology, 2(1): 1-13.

Olu-Owolabi, B.I.; Diagboya, P.N. and Adebowale, K.O.(2014) Evaluation of pyrene sorption-desorption on tropical soils. Journal of Environmental Management, 137:1-9. 
Pandey, R.; Prasad, R.L.; Ansari N.G. and Murthy, R.C. (2015) utilization of NaOH modified Desmostachya bipinnata (Kush grass) leaves and Bambusa arundinacea (bamboo) leaves for $\mathrm{Cd}(\mathrm{II})$ removal from Aqueous solution. Journal of Environmental Chemical Engineering, 3: 593-602.

Perez-Marin, A.B.; Zapata, V.M.; Ortuno, J.F.; Aguilar, M.; Saez, J and Llorens, M.(2007) Removal of cadmium from aqueous solutions by adsorption onto orange waste. Journal of Hazardous Materials B, 122-131.

Prapagdee, S.; Piyatiratitivorakul, S. and Petsom, A.(2014) Activation of cassava stem biochar by physico-chemical method for stimulating cadmium removal efficiency from aqueous solution. Environment Asia, 7(2):60-69.

Qiu, H.; Lu, L. V.; Pan, B.; Zhang, Q.; Zhang, W. and Zhang, Q. (2009) Critical Review in Adsorption Kinetic Models. Journal of Zhejiang University of Science A, 10(5): 716-724.

Rafatullah, M.; Sulaiman, O.; Hashim, R. and Ahmad, A. (2009) Adsorption of copper (II) chromium, nickel (II) and lead (II) ions from aqueous solutions by meranti sawdust. Journal of Hazardous Materials, 170: 969-977.

Rao, M.M.; Ramana, D.; Seshaiah, K.; Wang, M. and Chien, S. (2009) Removal of some metal ions by activated carbon prepared from Phaseolus aureus hulls, Journal of Hazardous Materials, 166:1006-1013.

Rao, K. S.; Mohapatra, M.; Anand, S. and Venkateswarlu, P. (2010) Review on Cadmium Removal from Aqueous Solutions. International Journal of Engineering, Science and Technology, 2(7): 81-103.

Rao, M. M.; Ramesh, A.; Rao, P. C.; Seshaiah, K. (2006) Removal of Copper and Cadmium from the aqueous solutions by activating carbon derived from ceiba pentandra hulls. Journal of Hazardous Materials, 129: 123-129.

Ribeiro, R.F.L.; Soares, V.C.; Costa, L.M. and Nascentes, C.C. (2015) Production of activated carbon from biodiesel solid residues: An alternative for hazardous metal sorption from aqueous solution. Journal of Environmental Management, 162: 123-131. 
Saeed, A.; Akhter, M.W. and Iqbal, M.(2005) Removal and recovery of heavy metals from aqueous solution using papaya wood as a new biosorbent, Separation and Purification Technology, 45(1): 25-31.

Salim, R; Al-Subu, M.M. and Sahrhage, E. (1992) Uptake of cadmium from water by beech leaves. Journal of Environmental Science \& Health, A27 (3):603-627.

Saleh, T.A.(2016) Nanocomposite of carbon nanotubes/silica nanoparticles and their use for adsorption of $\mathrm{Pb}(\mathrm{II})$ : from surface properties to sorption mechanism. Desalination and Water Treatment, 57:10730-10744.

Sanchez-Silva, L.; Lopez-Gonzalez, D.; Villasenor, J.; Sanchez, P. and Valverde, J. L. (2012) Thermogravimetric-mass spectroscopic analysis of lignocellulosic and marine biomass pyrolysis. Bioresource Technology, 109: 163-172.

Sarada, B.; Prasad, M. K.; Kumar, K. K. and Murthy, Ch. V. R. (2014) Cadmium removal by macro algae Caulerpa fastigiata: Characterization, kinetic, isotherm and thermodynamic studies. Journal of Environmental Chemical Engineering, 2: 1533- 1542.

Sardella, F.; Gimenez, M.; Navas, C.; Morandi, C.; Deiana, C. and Sapag, K. (2015) Conversion of viticultural industry wastes into activated carbon for removal of lead and cadmium. Journal of Environmental Chemical Engineering, 3(1): 253-260

Sari, A.; Mendil, D.; Tuzen, M. and Soulak, M. (2008) Biosorption of Cd(II) and Cr(III) from aqueous solution by moss (Hylocomium splendens) biomass: Equilibrium, kinetic and thermodynamic studies. Chemical Engineering Journal, 144: 1-9.

Sari, A. and Tuzen, M.(2009) Kinetic and equilibrium studies of biosorption of $\mathrm{Pb}(\mathrm{II})$ and $\mathrm{Cd}(\mathrm{II})$ from aqueous solution by macrofungus (Amanita rubescens) biomass. Journal of Hazardous Materials, 164:1004-1011.

Sen, T.K. (2012) Agricultural by-product biomass for removal of pollutants from aqueous solution by adsorption. Journal of Environmental Research and Development, 6(3):523-533.

Sengil, I.A.; Ozacar, M. and Turkmenler,H. (2009) Kinetic and isotherm studies of Cu(II) biosorption on valonia tannin resin. Journal of Hazardous Materials, 162:1046-1052. 
Sing, K. (2001) The use of nitrogen adsorption for the characterisation of porous materials. A: Physicochemical and Engineering Aspects, 187-188: 3-9.

Sing, K. S. W. (1982) Reporting Physisorption Data for Gas/Solid Systems with Special Reference to the Determination of Surface Area and Porosity. Pure \& Applied Chemistry, 54: 2201-2218.

Siswoyo, E.; Mihara, Y. and Tanaka, S. (2014) Determination of key components and adsorption capacity of a low cost adsorbent based on sludge of drinking water treatment plant to adsorb cadmium ion in water. Applied Clay Science, 97-98:146-152.

Stefany, P. M., Garcia, D.: Lopez, J. and Jimenez, A. (2005) Thermogravimetric Analysis of Composite obtained from sintering of Rice Husk scrap tire Mixtures. Journal of Thermal Analysis and Calorimetry, 81: 315-320.

Swiatkowski, A.; Pakula, M.; Biniak,S. and Walczyk, M.(2004) Influence of the surface chemistry of modified activated carbon on its electrochemical behaviour in the presence of lead(II) ions. Carbon, 42, (15):3057-3069.

Tan, X.; Liu, Y.; Zeng, G.; Wang, X.; Hu, X. and Gu, Y. (2015) Application of biochar for the removal of pollutants from aqueous solutions Chemosphere, 125: 70-85.

Taty-Costodes,V.C.; Fauduet, H.; Porte, C. and Delacroix, A. (2003) Removal of Cd(II) and $\mathrm{Pb}$ (II) ions, from aqueous solutions, by adsorption onto sawdust of Pinus sylvestris, Journal of Hazardous Materials, 105(1-3):121-142

Teker, M.; Imamoglu, M and Saltasbas, O.(1999) Adsorption of copper and cadmium ions by activated carbon from rice hulls. Turkish Journal of Chemistry, 23(2): 185-191.

Thirumavalavan, M.; Lai, Y. L. and Lee, J. F. (2011) Fourier transform infrared spectroscopic analysis of fruit peels before and after the adsorption of heavy metal ions from aqueous solution. Journal of Chemical Engineering Data, 56:2249-2255.

Titiloye, J.O.; AbuBakar, M.S., Odetoye, T.E. (2013) Thermochemical Characterisation of Agricultural Wastes from West Africa. Industrial Crops and Products, 47:199- 203. 
Tounsadi, H.; Khalidi, A.; Abdennouri, M.; Barka, N.(2015) Biosorption potential of Diplotaxis harra and Glebionis coronaria L. biomasses for the removal of Cd(II) and Co(II) from aqueous solutions, Journal of Environmental Chemical Engineering, 3(2):822-830.

Tsai, W. T.; Lai, C. W. and Hsien, K. J. (2006) Characterisation and adsorption properties of Diatomaceous earth modified by hydrofluoric acid etching. Journal of Colloid and Interface Science, 297: 749-754.

Tyowua, A.T.; Okieimen, F.E. and Ojeigbe, J.O. (2013) Equilibrium and kinetic studies of adsorption of $\mathrm{Cd}^{2+}$ and $\mathrm{Pb}^{2+}$ ions from aqueous solution by citric acid modified maize fibres. Chemical Sciences Journal, 93:1-9.

UNCTAD (2012) United Nations Conference on Trade and Development. Infocom Commodity Profile-Sweet Potato. Available internet: http://www.unctad.info/en/Infocomm/AACP-Products/COMMODITY-PROFILE---Sweetpotato Accessed on 10/11/2014

Volesky, B. (1990) Biosorption of heavy metals. CRC Press, Boca Raton, Florida.

Vaghetti, J. C. P; Lima, E. C.; Royer, B.; Cunha, B. M. C. and Cardoso, N. F. (2009) Pecan nutshell as biosorbent to remove $\mathrm{Cu}$ (II), $\mathrm{Mn}$ (II), and $\mathrm{Pb}$ (II) from aqueous solutions, Journal of Hazardous Materials, 162: 270-280.

Wahab, M.A.; Boubakri, H.; Jellai, S. and Jedial, N.(2012) Characterisation of ammonium retention processes onto cactus leaves fibres using FTIR, EDX and SEM analysis. Journal of Hazardous Materials, 241-242: 101-109.

Wan, S.; Ma, Z.; Xue, Y.; Ma, M.; Xu, S.; Qian, L. and Zhang, Q. (2014) Sorption of Lead (II), cadmium and Copper (II) ions from aqueous solution using tea waste. Industrial \& Engineering Chemistry Research, 53: 3629-3635.

Wasewar, K.L; Kumar, P.; Chand, S.; Padmini, B.N. and Teng, T.T.(2010) Adsorption of cadmium ions from aqueous solution using granular activated carbon and activated clay. Clean-Soil, Air, Water, 38(7):649-656.

Weber, W.J and Morris, J.C.(1963) Kinetics of adsorption on carbon from solution. Journal of the Sanitary Engineering Division, 89(2); 31-60. 
Wong, Y. C.; Szeto, V. S.; Cheung, W. H. and McKay, G. (2004) Adsorption of acid dyes on Chitosan-equilibrium isotherm analysis. Process Biochemistry 39: 693-702.

Xuan, Z.; Tang, Y.; Li, X.; Liu, Y. and Luo, F. (2006) Study on the equilibrium, kinetics and isotherm of Biosorption of lead ions onto presented chemically modified orange peel. Biochemical Engineering Journal 31: 160-164.

Yang, H.; Yan, R.; Chen, H.; Lee, D. H.; Zheng, C. (2007) Characteristics of hemicellulose, cellulose and lignin pyrolysis. Fuel 86: 1781-1788.

Zhang, V.; Zheng, R.; Zhao, J.; Ma, F.; Zhang, Y. and Meng, Q. (2014) Characterization of $\mathrm{H}_{3} \mathrm{PO}_{4}$-treated rice husk adsorbent and adsorption of copper (II) from aqueous solution. BioMed Research International, 496878. 


\section{Figures Captions}

Figure 1: $\mathrm{N}_{2}$ adsorption-desorption isotherm and pore size plot of PTPS residue adsorbent

Figure 2: Photograph of sweet potato (a) dried sweet potato peel (b) and pulverised sweet potato residue adsorbent-PTPS (c)

Figure 3: Electron micrograph of PTPS adsorbent (a), PTPS after Cd(II) sorption (b)

Scale bar: $300 / 200 \mu \mathrm{m}$

Figure 4: EDAX spectrum of PTPS residue adsorbent

Figure 5: EDAX spectrum of PTPS residue after Cd(II) adsorption

Figure 6: Thermogravimetric \& derivative thermogravimetric plot of PTPS in $\mathrm{N}_{2}\left(20-500{ }^{\circ} \mathrm{C}\right)$ $\& \operatorname{air}\left(500-600{ }^{\circ} \mathrm{C}\right)$

Figure 7: ATR-FTIR spectrum of Sweet potato adsorbent PTPS

Figure 8: ATR-FTIR spectrum of PTPS adsorbent after Cd(II) adsorption

Figure 9: Effect of $\mathrm{pH}$ on the sorption of $\mathrm{Cd}(\mathrm{II})$ ion onto PTPS adsorbent

Figure 10: Effect of contact time on Cd(II) ion sorption on PTPS adsorbent

Figure 11: Pseudo-first order (PFO) \& pseudo-second order (PSO) kinetic plot for PTPS adsorbent

Figure 12: Kinetic stages in intraparticle diffusion plot of $\mathrm{Cd}(\mathrm{II})$ ion sorption on PTPS residue

Figure 13: Kinetic stages in intraparticle diffusion plot of $\mathrm{Cd}(\mathrm{II})$ ion sorption on PTPS residue

Figure 14: Langmuir and Freundlich equilibrium isotherm modelling for $\mathrm{Cd}(\mathrm{II})$ sorption on PTPS residue.

Figure 15: Langmuir Isotherm Separation factor plot for PTPS adsorbent 


\section{Tables Captions}

Table 1: Physical and chemical characteristics of PTPS adsorbent

Table 2: XRF of PTPS residue adsorbent

Table 3: Initial and final $\mathrm{pH}$ of adsorbate solution for PTPS sorption of $\mathrm{Cd}(\mathrm{II})$

Table 4: Kinetic models parameters for Cd(II) sorption on PTPS adsorbent

Table 5: Isotherm model parameters for sorption of Cd(II) onto PTPS adsorbent

Table 6: $\mathrm{Cd}(\mathrm{II})$ Langmuir constant $\mathrm{q}_{\max }$ of this study with those reported in literature 